\title{
A Rhodopsin Gene Mutation Responsible for Autosomal Dominant Retinitis Pigmentosa Results in a Protein That Is Defective in Localization to the Photoreceptor Outer Segment
}

\author{
Ching-Hwa Sung, ${ }^{1,4}$ Clint Makino, ${ }^{5}$ Denis Baylor, ${ }^{5}$ and Jeremy Nathans ${ }^{1.2 .3 .4}$ \\ 'Department of Molecular Biology and Genetics, ${ }^{2}$ Department of Neuroscience, ${ }^{3}$ Wilmer Ophthalmologic Institute, \\ ${ }^{4}$ Howard Hughes Medical Institute, Johns Hopkins Medical School, Baltimore, Maryland 21205 and ${ }^{5}$ Department of \\ Neurobiology, Stanford University, Stanford, California 94305
}

\begin{abstract}
Over 45 mutations in the rhodopsin gene have been identified in patients with autosomal dominant retinitis pigmentosa, Including a cluster near the extreme carboxy-terminus, a region of the protein for which no function has yet been assigned. To elucidate the biochemical defect(s) in this group of mutants, we have studied a naturally occurring stop codon mutation that removes the last five amino acids of rhodopsin (Q344ter). When produced in transfected tissue culture cells, the mutant protein is indistinguishable from the wild type in light-dependent activation of the photoreceptor G-protein (transducin), and in serving as a light-dependent substrate for rhodopsin kinase. Mice that express a Q344ter transgene in rod photoreceptors show nearly normal light responses as determined by suction electrode recordings of the membrane current from single rod outer segments; the main difference between transgenic and nontransgenic responses is a $15 \%$ longer time-to-peak in the response of transgenic rods. In the Q344ter transgenic retina, direct immunofluorescent staining with antibodies specific for either wildtype or Q344ter rhodopsin shows abnormal accumulation of the Q344ter, but not the endogenous rhodopsin, in the plasma membrane of the photoreceptor cell body. These data indicate that rhodopsin's carboxy-terminus is required for efficient transportation to or retention in the outer segment.

[Key words: retinitis pigmentosa, rhodopsin, outer segment, protein sorting, rod photoreceptor, transgenic mice, retina]
\end{abstract}

\footnotetext{
Received Jan. 26, 1994; revised Mar. 18, 1994; accepted Apr. 13, 1994.

We thank Ms. Erin Cooke, Ms. Ying Zhao, and Drs. William Ried and Don Cleveland for injection and implantation of mouse eggs; Ms. Lijuan Zhou for assistance with animal care; Ms. Carol Davenport, Ms. Jeanine Ptak, and Dr. Clark Riley for synthetic peptides and oligonucleotides; Drs. Robert Molday and Paul Hargrave for gifts of mAbs 1D4 and B6-30, respectively; Dr. Lubert Stryer and the Hoffman-La Roche Company for gifts of 11-cis retinal; Drs. Tom Neubert and Jim Hurley for advice on the purification of transducin; Mr. Michael Delannoy for instruction in the use of the confocal laser scanning microscope; and Drs. Randall Reed, Mengqing Xiang, and King-wai Yau, and Ms. Jennifer Macke for comments on the manuscript. This work was supported by the National Retinitis Pigmentosa Foundation (C.-H.S., J.N.), the Alcon Research Institute (J.N.), the Howard Hughes Medical Institute (J.N.), the National Eye Institute (Grant EY05750, D.B.), and the Ruth and Milton Steinbach Fund (J.N. and D.B.).

Correspondence should be addressed to Dr. Jeremy Nathans, 805 PCTB, Johns Hopkins University School of Medicine, 725 North Wolfe Street, Baltimore, MD 21205.

Copyright (C) 1994 Society for Neuroscience $0270-6474 / 94 / 145818-16 \$ 05.00 / 0$
}

Rhodopsin is the light-absorbing protein that mediates vision at low levels of illumination. It resides in rod photoreceptors, which in humans comprise approximately $95 \%$ of retinal photoreceptors. Rhodopsin is a G-protein-coupled receptor composed of an integral membrane apoprotein (opsin) joined covalently to a chromophore, 11-cis retinal. Photoisomerization of retinal from 11-cis to all-trans induces a conformational change in the apoprotein, leading to a conformation that is competent to activate the photoreceptor-specific G-protein transducin, thereby initiating the phototransduction cascade.

Each vertebrate photoreceptor elaborates a specialized cilium-referred to as an outer segment - that houses the phototransduction machinery. The outer segment contains hundreds of flattened membrane sacs (also called disks) stacked in close apposition. In mammals, an average rod outer segment measures $1.5 \mu \mathrm{m}$ in diameter and $30 \mu \mathrm{m}$ in length and contains approximately $5 \times 10^{7}$ molecules of rhodopsin embedded within the disk and plasma membranes (Knowles and Dartnall, 1977). The protein composition of purified outer segments is striking in its simplicity: rhodopsin comprises $80 \%$ of the total protein, and the half-dozen other abundant proteins are all involved in the phototransduction cascade (Kuhn, 1984).

Photoreceptor outer segments and their constituent proteins are continuously renewed throughout the life of the organism, turning over every $10 \mathrm{~d}$ in mammals (reviewed in Knowles and Dartnall, 1977). Synthesis of outer segment proteins occurs in the photoreceptor cell body proper, and the newly synthesized proteins are transported along a thin connecting cilium to the outer segment. In the cell body, opsin is synthesized on the rough endoplasmic reticulum, transported through the Golgi apparatus, and targeted initially to the plasma membrane. At the base of the outer segment, plasma membrane containing newly synthesized opsin evaginates to form new disks. At the distal end of the outer segment, the retinal pigment epithelial cells phagocytose approximately $10 \%$ of the outer segment per day.

In humans, inherited disorders of rod function are often accompanied by a progressive loss of photoreceptor viability, leading eventually to blindness. This combination of symptoms is referred to as retinitis pigmentosa (RP), a group of inherited disorders that affects approximately one in 4000 people (Heckenlively, 1988). RP is both clinically and genetically heterogeneous, comprising X-linked, autosomal dominant, and autosomal recessive forms. During the past several years, defects in 
the genes encoding several rod outer segment proteins-rhodopsin (Dryja et al., 1991; Sung et al., 1991a; Inglehearn et al., 1992), peripherin/rds (Kajiwara et al., 1991; Farrar et al., 1993), and the $\beta$ subunit of the cGMP phosphodiesterase (McLaughlin et al., 1993)-have been identified in patients with RP. Over 45 different rhodopsin gene mutations have been identified in families with autosomal dominant RP, together accounting for one-quarter of patients with autosomal dominant inheritance (reviewed in Nathans et al., 1992).

Analysis of 34 of the mutant opsins associated with autosomal dominant RP using a tissue culture system has revealed two distinct classes of biochemical defects (Sung et al., 1991b, 1993). Approximately $85 \%$ of the mutant proteins (class II) are produced at lower levels than the wild type, accumulate predominantly in the endoplasmic reticulum, and bind 11-cis retinal variably or not at all. This class appears to be defective in folding and/or stability. The remaining $15 \%$ of mutant proteins (class I) resemble the wild type in the tissue culture system. They are produced at high levels, accumulate in the plasma membrane, and bind efficiently to 11 -cis retinal in vitro to form photolabile pigments. Interestingly, most of the class I mutants map very close to the carboxy-terminus, a region of the protein for which no function has yet been assigned. Because these rhodopsin gene mutations were identified in the heterozygous condition in patients with autosomal dominant RP, it seems likely that the mutant proteins interfere with or participate aberrantly in some physiological process. A second possibility is that they are physiologically silent and that RP results from haploinsufficiency, a scenario that seems unlikely in light of the finding that heterozygous carriers of one apparently null mutation in the rhodopsin gene do not have RP (Rosenfeld et al., 1992).

The experiments reported here were aimed at identifying the biochemical defect(s) in one of the carboxy-terminal mutants, glutamine ${ }^{344}$-to-termination codon (Q344ter). They show that the carboxy-terminus is required for rhodopsin's efficient transportation to or retention in the outer segment, and imply that this region of rhodopsin is recognized by onc or morc factors that are involved in establishing or maintaining the correct protein composition of the outer segment.

\section{Materials and Methods}

Generation of transgenic animals. An $11 \mathrm{~kb}$ segment containing the mouse rhodopsin gene, including $4.5 \mathrm{~kb}$ of $5^{\prime}$ flanking DNA, was isolated from a gel fractionated BamHI complete digest genomic library prepared from Balb/c liver DNA (Zack et al., 1991). The insert was transferred into pUC118, and from this plasmid a subclone was generated that contained a $2.8 \mathrm{~kb}$ XbaI-BamHI fragment derived from the $3^{\prime}$ end of the insert. For both the Q344ter and wild-type rhodopsin transgenes, a PCR product spanning the BspEI-MscI fragment in exon 5 was synthesized using the cloned genomic DNA as template (see Fig. 2). In both cases the 5' primer, which encompasses the BspEI site near the 5' end of exon 5, was 5'-CAACTGAATTCGCCTTCCAGTTCCGGAACTGTATGCTC. For the Q344ter transgene, the $3^{\prime}$ primer was $5^{\prime}$ ACAGTCTCTGGCCAGGCTTAGGCTGGATCCACCTAGCTGGTCTCCGTCTTGG; and for the wild type transgene the 3' primer was 5'-ACAGTCTCTGGCCAGGCTTAGGCTGGCGCCACCTGGCTGGTCTCC. Both 3' primers encompass the MscI site immediately $3^{\prime}$ of the stop codon, and each introduces into the PCR product the nucleotide differences shown above and in Figure 2 (on the opposite strand) in boldface. The PCR products were digested with BspEI and MscI and inserted in place of the corresponding BspEI-Mscl fragment in the 2.8 $\mathrm{kb}$ XbaI-BamHI subclone. After subcloning, the region corresponding to the PCR product was sequenced to check for spurious mutations and to confirm the predicted mutations. For each construct, the $11 \mathrm{~kb}$ BamHI fragment containing the engineered mutation was reassembled and propagated in $E$. coli. For injection, the $11 \mathrm{~kb}$ fragments were isolated by cutting with unique flanking polylinker restriction sites and purified by agarose gel electrophoresis. Transgenic mice were generated by pronuclear injection of B6AF1 (female) $\times$ C57BL/6J (male) embryos, using established techniques (Hogan et al., 1986).

Mice were screened by PCR amplification of tail DNA prepared as described in Wang et al. (1992) using primers that flank the engineered restriction sites, 5'-GCCTCCCAGTTCCGGAACTGTATG and 5'TGGATGCCCTTTGTCAAGCTGTCC. The PCR products were phenol/chloroform extracted, digested with BamHI or HhaI to test for the Q344ter or wild-type transgenes, respectively, and analyzed on a $4 \%$ Nusieve agarose gel.

Preparation of antibodies. For immunization, a synthetic peptide, $\mathrm{H}_{2} \mathrm{~N}$-CSATASKTETS-COOH, was prepared in which the carboxy-terminal 10 amino acids correspond to the last 10 amino acids of mouse Q344ter rhodopsin. An amino-terminal cysteine residue was added to provide a sulfhydryl group for peptide conjugation to BSA using the heterobifunctional cross-linking reagent succinimidyl 4- $N$-maleimidomethyl) cyclohexane-1-carboxylate (SMCC; Pierce) as previously described (Lerner et al., 1981). In brief, $10 \mathrm{mg}$ of BSA and $10 \mathrm{mg}$ of SMCC

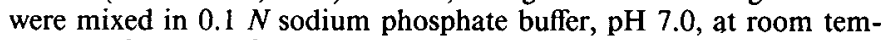
perature for $1 \mathrm{hr}$, after which unreacted SMCC was removed by chromatography on a Sephadex G25 column equilibrated with $0.1 \mathrm{~N}$ sodium phosphate, pH 6.0. The fractions containing the SMCC-BSA conjugate were pooled and incubated with $10 \mathrm{mg}$ of peptide overnight at room temperature. The peptide-BSA conjugate was purified from residual free peptide by chromatography on a Sephadex G25 column equilibrated

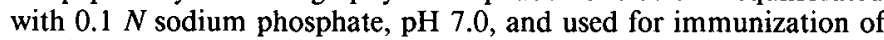
rabbits.

For the construction of bacterial fusion proteins, DNA segments encoding either the carboxy-terminal 27 amino acids of human rhodopsin or the carboxy-terminal 22 amino acids of the Q344ter mutant were inserted at the $3^{\prime}$ end of the open reading frame encoding the $E$. coli maltose-binding protein (MBP) in expression vector pMAL (New England Biolabs). The MBP fusion proteins were obtained from $E$. coll following induction by IPTG and were purified by amylose affinity chromatography (New England Biolabs). For affinity purification of rabbit antibodies against Q344ter (serum JH778), $1.5 \mathrm{mg}$ of pMAL-Q344ter fusion protein was covalently coupled to a $2 \mathrm{ml}$ Aminolink column (Pierce), $1-5 \mathrm{ml}$ of serum was absorbed to the column in phosphatebuffered saline (PBS), and antibodies specific for the fusion protein were eluted in $0.1 \mathrm{M}$ glycine, $\mathrm{pH} 2.8$.

MAbs 1D4 (Hodges et al., 1988) and B6-30 (Adamus et al., 1988) were prepared from mouse ascites by caprylic acid precipitation followed by ammonium sulfate precipitation (Harlow and Lane, 1988). For conjugation to rhodamine or fluorescein, affinity-purified $\mathrm{JH} 778$ and purified 1D4 and B6-30 were concentrated using a Centricon 30 spin column (Amicon) to approximately $10 \mathrm{mg} / \mathrm{ml}$ in $50 \mathrm{~mm}$ sodium bicarbonate buffer, $\mathrm{pH} 8.5-9.0$. NHS-fluorescein $(0.1 \mathrm{mg}$ per $10 \mathrm{mg}$ protein; Pierce) or NHS-rhodamine ( $0.2 \mathrm{mg}$ per $10 \mathrm{mg}$ protein) in DMSO were incubated with cach antibody for $2 \mathrm{hr}$ on icc, and the conjugatcd antibodies were purified either on a centricon spin column or by Sephadex G25 column chromatography to remove unbound fluorescent dye.

Transfection and immunostaining of tissue culture cells. 293S cells were transfected with cDNAs encoding Q344ter or wild-type human rhodopsin inserted into expression vector pCIS using the calcium phosphate precipitation method (Gorman et al., 1990). Cells were immunostained $16 \mathrm{hr}$ after transfection as previously described (Sung et al., 1991b).

Immunoblot analysis. Bacterial fusion protein or membrane fractions prepared from 293S stable cell lines expressing wild-type or Q344ter human rhodopsin were analyzed by SDS-PAGE, and detected by Western blotting as previously described (Sung et al., 1991b).

Histochemistry and immunocytochemistry. Eyes were enucleated, fixed in $4 \%$ paraformaldehyde for more than $4 \mathrm{hr}$ at $4^{\circ} \mathrm{C}$, snap-frozen in 2-methylbutane prechilled in liquid nitrogen, and embedded in OCT compound; $10 \mu \mathrm{ml}$ sections were cut in a cryostat at $-20^{\circ} \mathrm{C}$ and mounted on gelatin-coated slides. Hematoxylin and eosin staining was used for conventional histochemical analysis. For immunostaining, mounted sections were rinsed in PBS containing $2 \mathrm{mM} \mathrm{MgCl}_{2}$ (Mg-PBS) and incubated with $5 \%$ normal goat serum for $30 \mathrm{~min}$, rinsed in Mg-PBS, and incubated with fluorescent dye-conjugated antibodies for $2 \mathrm{hr}$ at room temperature. After three washes in $\mathrm{Mg}$-PBS, the sections were mounted in $\mathrm{Mg}$-PBS containing $90 \%$ glycerol and $0.1 \% p$-phenylene diamine. 


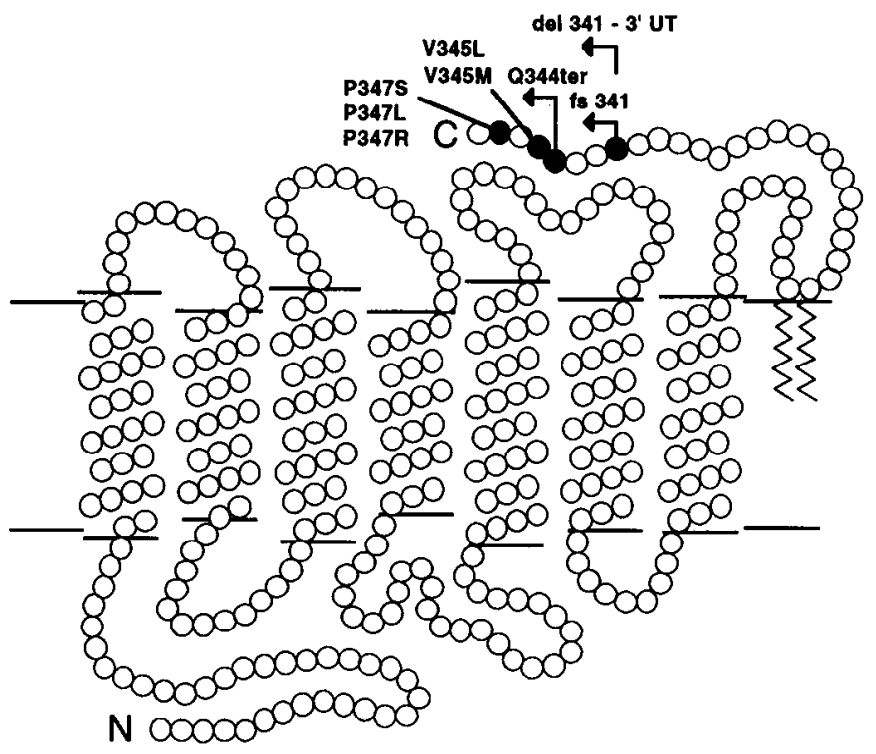

Figure 1. Transmembrane model of human rhodopsin showing the locations of mutations near the carboxy-terminus responsible for autosomal dominant retinitis pigmentosa. Eight mutations are shown: del $341-3^{\prime} U T$, a 42 bp deletion that removes the last eight codons (Restagno et al., 1993); $f s 341$, an 8 bp deletion begining in codon 341 (ApfelstedtSylla et al., 1993); Q344ter (Sung et al., 1991a); V345M (Dryja et al., 1991); V345L (Rosas et al., 1994); P347L (Dryja et al., 1990; Sung et al., 1991; Inglehearn et al., 1992); P347S (Dryja et al., 1990); P347R (Gal et al., 1991). Horizontal lines indicate the approximate extent of the lipid bilayer; The two zigzag lines represent palmitic acid groups. $N$ and $C$ mark the amino- and carboxy-termini, respectively. The carboxy-terminus faces the cytosol. $f s$, frameshift; del, deletion.

For quantitative confocal laser scanning microscopy, $4.5 \mu \mathrm{m}$ thick optical sections were examined through a \#1 neutral density filter using a Bio-Rad MRC 600 confocal laser scanning microscope equipped with a photomultiplier tube and comos version 6.03 software. The gain and black levels were set so that for each stained section the maximum signal intensity corresponded to the red level on the false color image, within the linear portion of the response curve. The only exception to this protocol was in the recording of $\mathrm{JH} 778$ staining of nontransgenic retinas, in which case the gain and black levels were held at the level determined by immunostaining of a Q344ter retina section with the same antibody. Two fields were recorded for each stained retina section. To analyze the intensity of staining in different areas within a section, the light intensity was calculated for a series of adjacent $30 \mu \mathrm{m} \times 2.5 \mu \mathrm{m}$ boxes, aligned with their long edges parallel to the plane of the retina and together covering the thickness of the photoreceptor cell layer.

Quantitation of transgene expression. RNA from individual mouse retinas was purified using the guanidinium/phenol method (Chomczinski and Sacchi, 1987). Following chloroform extraction and isopropanol precipitation, the RNA was dissolved in $20 \mu \mathrm{l}$ of water. For a $20 \mu \mathrm{l}$ cDNA synthesis reaction, $2 \mu \mathrm{l}$ of RNA (preheated to $65^{\circ} \mathrm{C}, 2 \mathrm{~min}$ ) was incubated with $0.45 \mathrm{OD} \mathrm{d}(\mathrm{N})_{6}$ and $100 \mathrm{U}$ of MoMLV reverse transcriptase (Bethesda Research Labs) in $50 \mathrm{~mm}$ Tris, pH 7.6, $70 \mathrm{~mm} \mathrm{KCl}$, $10 \mathrm{mM} \mathrm{MgCl}_{2}, 10 \mathrm{~mm} \mathrm{DTT}$, and $1 \mathrm{~mm}$ of each of the four dNTPs at $37^{\circ} \mathrm{C}$ for $1 \mathrm{hr} .10 \%$ of a cDNA synthesis reaction was used as template for PCR amplification with primers CS120 (5'-AGAACACTGAGGGAGCCTGCATGACCTC) and CS107 (5'-TAACCCGGTCATCTACATCATGTTGAAC) as shown in Figure 4. After residual primers were removed using a Microspin 100 column (Amicon), $7.5 \mathrm{ng}$ of ${ }^{32} \mathbf{P} 5$ '-end-labeled primer CS121 (5'-CTGTATGCTCACCACGCTGTGCTGC) was added to the $222 \mathrm{bp}$ PCR product; the mixture

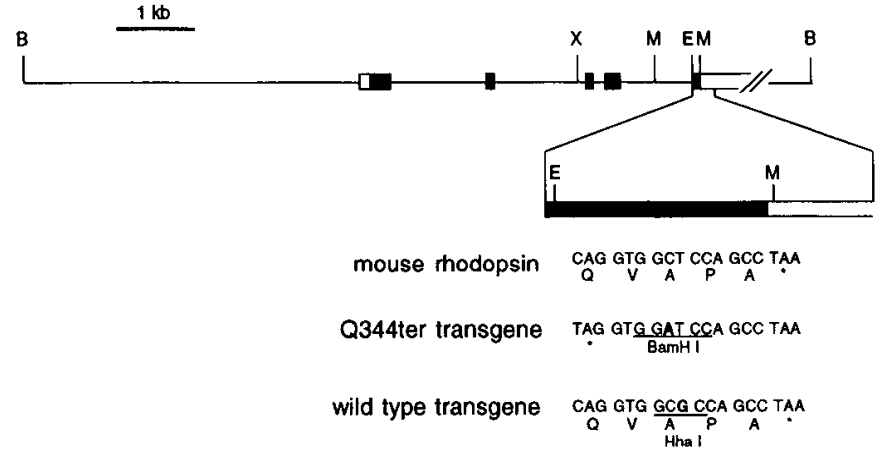

Figure 2. Mouse rhodopsin transgene constructs. Top, Partial restriction map of the $11 \mathrm{~kb}$ mouse rhodopsin gene fragment. Boxes indicate the exons. Solid boxes, protein coding region; open boxes, noncoding sequences. Diagonal lines indicate that the $3^{\prime}$ end of the transcription unit has not been precisely defined. Bottom, Enlarged map of exon 5 showing the engineered DNA sequence changes (boldface letters) and the resulting coding and restriction site differences in the Q344ter and wild-type rhodopsin transgenes. $B$, BamHI; $E$, BspEI; $M$, MscI; $X$, XbaI; *, stop codon.

was boiled for $2 \mathrm{~min}$ and then cooled on dry ice. DNA extension was performed in the presence of all four dNTPs at $37^{\circ} \mathrm{C}$ for $30 \mathrm{~min}$ using a modified T7 DNA polymerase (Sequenase 2.0, U.S. Biochemicals). Following heat inactivation of the DNA polymerase, one-half of the sample was digested with BamHI (for Q344ter transgenic samples) or Hhal (for wild-type rhodopsin transgenic samples). To assess the enzyme digestion, a ${ }^{32} \mathrm{P} 5$-end-labeled fragment of $239 \mathrm{bp}$, obtained by PCR amplifying the corresponding transgene plasmid clones over the same region, was added as an internal control to each sample prior to enzyme addition. The two halves of the sample were treated with proteinase $\mathrm{K}$, heat denatured in formamide loading buffer, and run on a $6 \%$ sequencing gel. For quantitation, autoradiograms were scanned using an LKB Ultroscan XL laser densitometer.

Transducin and rhodopsin kinase assays. Transducin was purified to apparent homogeneity by GTP elution from bovine rod outer segments as described by Kuhn (1982), and rhodopsin kinase was partially purified from bovine rod outer segments by $\mathrm{KCl}$ extraction as described by Sitaramayya (1986). Wild-type and Q344ter human rhodopsins were prepared from stable $293 \mathrm{~S}$ cell lines transfected with the corresponding cDNA clones in the pCIS expression vector (each cell line produces approximately $3 \times 10^{6}$ molecules of opsin per cell; Sung et al., 199lb). In brief, total cell membranes were purified on a sucrose shelf, incubated with 11-cis retinal for several hours in the dark, sonicated for $10 \mathrm{sec}$ in $5 \mathrm{~m}$ urea to remove peripheral membrane proteins (Shichi and Somers, 1978), and recovered by ultracentrifugation. After the addition of 11cis retinal, all manipulations were carried out in the dark or under dim red light. The membrane pellets were solubilized in $70 \mathrm{mM} \mathrm{KPO}_{4}, \mathrm{pH}$ $7.5,5 \mathrm{mM} \mathrm{MgCl}_{2}, 2 \mathrm{~mm}$ DTT (RK buffer) containing $0.3 \%$ dodecylmaltoside to give a final rhodopsin concentration of $0.75 \mu \mathrm{M}$ as determined spectrophotometrically.

For transducin assays, $20 \mu \mathrm{l}$ of rccombinant rhodopsin was combincd with $5 \mu$ l of $5 \mathrm{~mm}$ Tris, pH 7.5, $0.5 \mathrm{~mm} \mathrm{MgCl}_{2}, 1 \mathrm{~mm}$ DTT, $0.1 \mathrm{~mm}$ PMSF, and $0.1 \mathrm{mM}$ GTP containing $0.5 \mu \mathrm{M}$ transducin. The reaction was initiated by the addition of $20 \mu \mathrm{l}$ of RK buffer containing $5 \mu \mathrm{Ci}$ of ${ }^{35}$ S-GTP- $\gamma$-S and was maintained at room temperature throughout the experiment. At intervals of $1 \mathrm{~min}, 5 \mu \mathrm{l}$ aliquots were removed and assayed for ${ }^{35} \mathrm{~S}-\mathrm{GTP}-\gamma-\mathrm{S}$ binding to transducin by filter binding using a slot-blot format. The ${ }^{35} \mathrm{~S}$ retained by the filter was measured using a Molecular Dynamics Phosphor-Imager. Two reactions were prepared for each rhodopsin sample: one was maintained in the dark, and the other was exposed for $1 \mathrm{~min}$ to a broad-band fiber optic light of sufficient intensity to photoactivate $>95 \%$ of the rhodopsin. In a control exper-

Figure 3. Histologic appearance of transgenic and nontransgenic retinas. Paraformaldehyde fixed and frozen sections of retinas from the following transgenic $(A-D)$ and nontransgenic $(E, F)$ lines were stained with hematoxylin and eosin: $A, \mathrm{Q} 344$ ter-9 at $\mathrm{P} 19 ; B$, a derivative of $\mathrm{Q} 344$ ter-9 with increased transgene expression at $\mathrm{P} 23 ; C$, wild type-1 at $\mathrm{P} 10 ; D$, wild type-1 at $\mathrm{P} 20 ; E$, nontransgenic at $\mathrm{P} 10 ; F$, nontransgenic at $\mathrm{P} 25$. Photoreceptor cell loss is apparent in $B-D$. RPE, retinal pigment epithelium; $O S$, outer segments; $I S$, inner segments; $O N L$, outer nuclear layer; $O P L$, outer plexiform layer; $I N L$, inner nuclear layer; $I P L$, inner plexiform layer; $G C L$, ganglion cell layer. The brackets indicate the photoreceptor cell layer. 

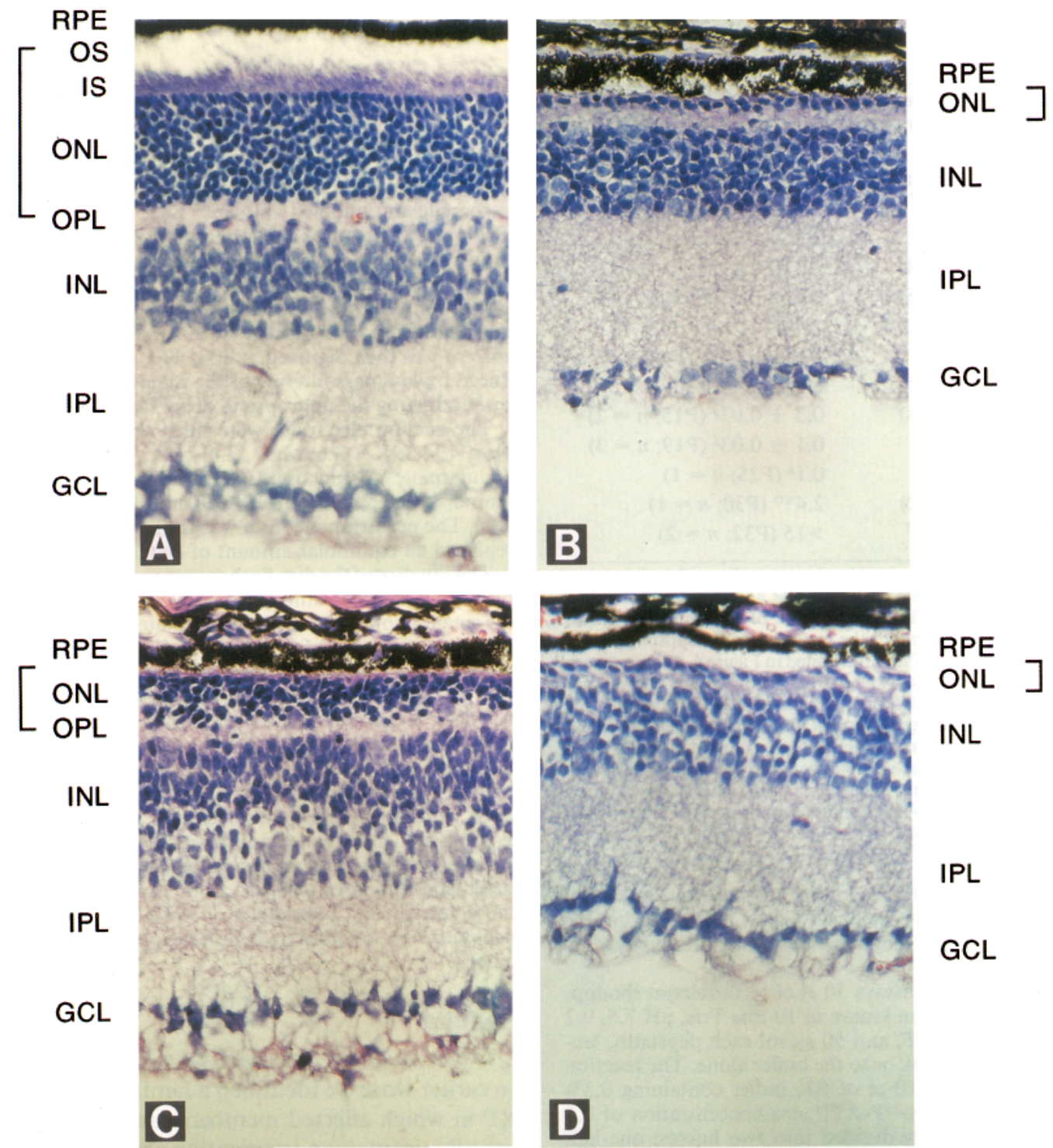

RPE

ONL ]

INL

IPL
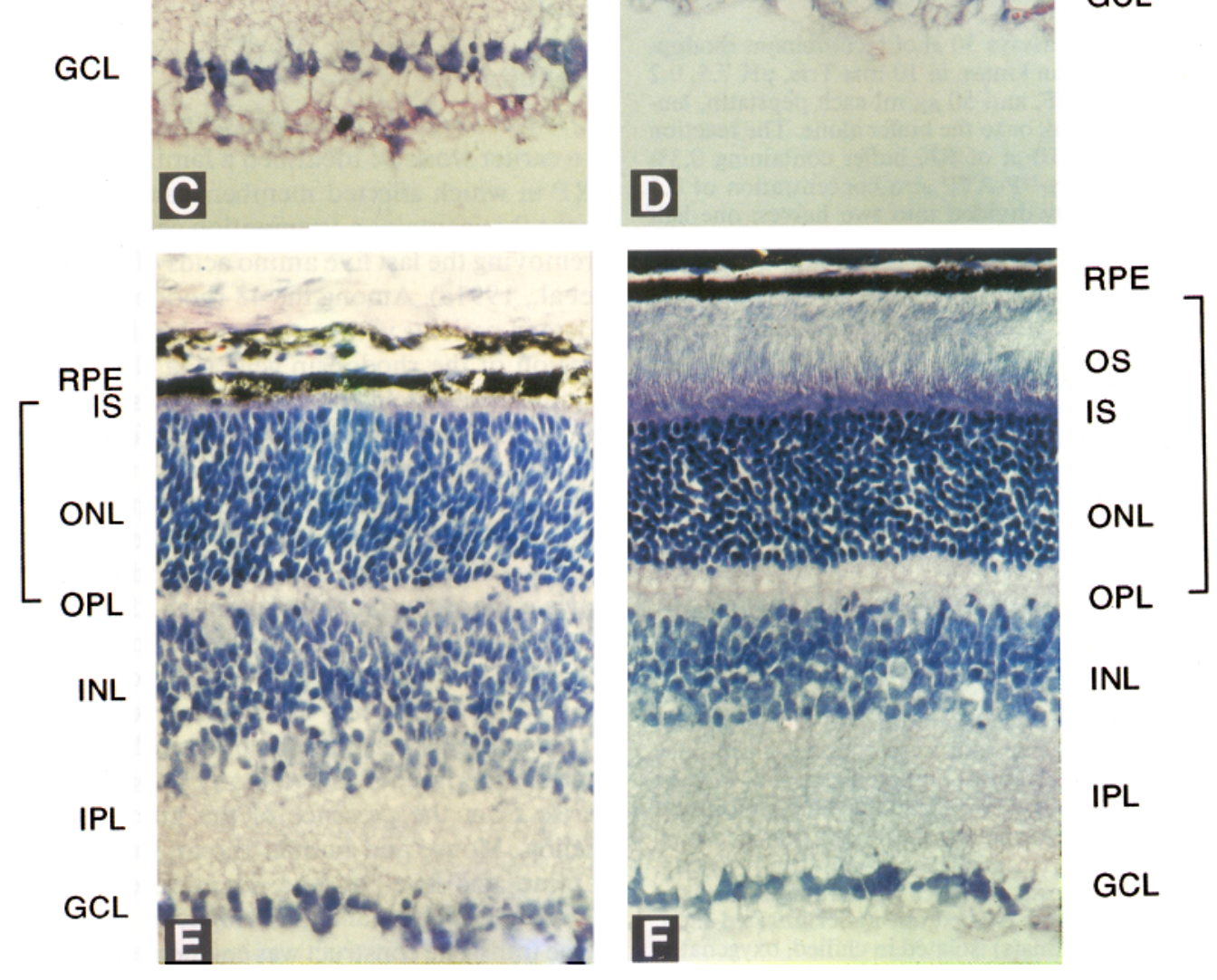

INL

IPL

GCL 
Table 1. Time course of photoreceptor loss and level of transgene expression in Q344ter and wild-type rhodopsin transgenic mice

\begin{tabular}{lll} 
Line & $\begin{array}{l}\text { Average time for } \\
\text { loss of }>50 \% \text { of } \\
\text { photoreceptors }\end{array}$ & $\begin{array}{l}\text { Ratio of transcripts } \\
\text { (transgene/endogenous } \\
\text { gene) }\end{array}$ \\
\hline Q344ter-1 & $<3$ weeks $(n=4)$ & $1.3^{c}(\mathrm{P} 22 ; n=1)$ \\
Q344ter-9 & $>7$ weeks $(n=31)$ & $0.8 \pm 0.3^{b}(\mathrm{P} 19 ; n=6)$ \\
Q344ter-20 & 3-4 weeks $(n=17)$ & $1.4^{a}(\mathrm{P} 10 ; n=1)$ \\
& & $1.6 \pm 0.3^{b}(\mathrm{P} 18 ; n=5)$ \\
Wild type-1 & $<2$ weeks $(n=9)$ & $5.2 \pm 1.4^{b}(\mathrm{P} 10 ; n=3)$ \\
Wild type-29 & $>8$ weeks $(n=8)$ & $0.3 \pm 0.03^{a}(\mathrm{P} 15 ; n=2)$ \\
& & $0.1 \pm 0.03^{b}(\mathrm{P} 19 ; n=3)$ \\
Wild type-48 & $<3$ weeks $(\mathrm{n}=2)$ & $0.1^{b}(\mathrm{P} 25 ; n=1)$ \\
Wild type-50 & ND & $>14^{\mathrm{ND}}(\mathrm{P} 30 ; n=1)$ \\
\end{tabular}

Photoreceptor loss was estimated by examining hematoxylin and eosin-stained sections at various ages from the indicated number of animals, and comparing the number of nuclei in the outer nuclear layer to that of age-matched controls. The ratio of expression of the transgene to the endogenous rhodopsin gene was determined by reverse transcriptase/PCR as illustrated in Figure 4 . In each reverse transcriptase/PCR experiment, one eye was used for histochemical analysis and the other eye used for preparation of RNA. Nineteen retinas were judged to be too degenerated for the RNA from the contralateral retina to be considered useful. The degree of degeneration of the retina contralateral to those used for preparation of RNA are abbreviated as follows: $a$, no apparent degeneration; $b$, moderate degeneration $(30-90 \%$ of photoreceptor nuclei remaining and outer segments shortened); $c$, severe degeneration $(0-30 \%$ of photoreceptor nuclei remaining and no outer segments). ND, not determined.

iment, serial dilution of solubilized recombinant rhodopsin into solubilized membranes from nontransfected $293 \mathrm{~S}$ cells indicated that the transducin assay was in the linear range with respect to rhodopsin concentration (data not shown).

For rhodopsin phosphorylation assays $30 \mu \mathrm{l}$ of recombinant rhodopsin was added to $20 \mu \mathrm{l}$ of rhodopsin kinase in $10 \mathrm{~mm}$ Tris, $\mathrm{pH} 7.5,0.2$ $\mathrm{M} \mathrm{KCl}, 5 \mathrm{~mm}$ DTT, $0.5 \mathrm{~mm}$ PMSF, and $50 \mu \mathrm{g} / \mathrm{ml}$ each pepstatin, leupeptin, benzamidine, and aprotinin, or to the buffer alone. The reaction was initiated by the addition of $10 \mu \mathrm{l}$ of $\mathrm{RK}$ buffer containing $0.3 \%$ dodecylmaltoside and $10 \mu \mathrm{Ci}$ of $\gamma-{ }^{32} \mathrm{P}-\mathrm{ATP}$ at a concentration of 0.5 mM. The sample was immediately divided into two halves: one-half was incubated at room temperature for $30 \mathrm{~min}$ in the dark, and the other half was incubated at room temperature for 30 min under continuous illumination at a flux sufficient to photoactivate the rhodopsin with a $t_{1 / 2}$ of approximately $1 \mathrm{~min}$. SDS/PAGE and autoradiography of the entire reaction showed a single band that was phosphorylated in a light- and rhodopsin kinase-dependent manner, and this band had the mobility expected for recombinant rhodopsin. Several proteins were observed to be phosphorylated independent of light or the addition of rhodopsin kinase. For immunoprecipitation, the kinase reaction was terminated by the addition of EDTA to $50 \mathrm{~mm}$, and the rhodopsin immunoprecipitated with an excess of $\mathrm{mAb} B 6-30$. Radiolabeled opsin was released by boiling in SDS sample buffer, resolved by SDS/PAGE, and visualized by autoradiography.

Suction electrode recordings. Prior to recording from Q344ter-9 transgenic mice, one eye from each mouse was removed and processed for immunostaining with $\mathrm{JH} 778$ as described above. The other eye was used for electrophysiological analysis only if the Q344ter protein was found to be uniformly produced across the retina. All electrophysiological results from Q344ter transgenic rods were obtained from mice with little or moderate retinal degeneration. Transgenic mice 3-4 weeks old or wild-type mice 3-17 weeks old were dark adapted for a minimum of $7.5 \mathrm{hr}$. The procedures for preparing the tissue and for recording responses from the rods were as described in Raport et al. (1994). Briefly, mice were sacrificed by $\mathrm{CO}_{2}$ narcosis and decapitated under dim red light. All subsequent procedures were carried out under infrared light. The eye(s) was removed and the retina(s) isolated in chilled, oxygenated Leibovitz's L-15 medium (GIBCO). The retina was placed photoreceptor side up on a glass capillary array ( 8 or $50 \mu \mathrm{m}$ diameter capillaries; Gallileo Electro-optics Corp., Sturbridge, MA), where it was held by mild suction applied from beneath the array, allowing the vitreous humor to be removed by passing a razor blade between the retina and the array. The retina was stored in L-15 medium on ice until use. A portion of the retina was chopped with a razor blade mounted on a lever arm; small pieces and individual rods were then placed in an experimental chamber. The chamber temperature was held at $36-38^{\circ} \mathrm{C}$ by perfusing continuously with heated medium. The medium was buffered with bicarbonate and bubbled with $95 \% \mathrm{O}_{2}, 5 \% \mathrm{CO}_{2}$, bringing the $\mathrm{pH}$ to 7.4 . The outer segment of an isolated rod or a rod in a piece of tissue was drawn into a suction electrode connected to a current-to-voltage converter. Membrane current recordings were filtered with an 8-pole Bessel low-pass filter whose $-3 \mathrm{~dB}$ point was set at $30 \mathrm{~Hz}$; in a few experiments, the bandwidth was limited to 20 or $50 \mathrm{~Hz}$. The filtered membrane current was then digitized at 200,400 , or $1000 \mathrm{~Hz}$. The time lag introduced by low-pass filtering of the membrane current was compensated by subtracting the appropriate delay from the measured response.

The suction electrodes were filled with a solution containing (mM) $\mathrm{Na}^{+}, 134.5 ; \mathrm{K}^{+}, 3.6 ; \mathrm{Mg}^{2+}, 2.4 ; \mathrm{Ca}^{2+}, 1.2 ; \mathrm{Cl}^{-}, 136.3 ;$ succinate ${ }^{-2}, 3$; L-glutamate ${ }^{-1}$, 3; glucose, 10; HEPES buffer, 10; EDTA, 0.02; and BME amino acid supplement (GIBCO) and BME vitamin supplement (GIB$\mathrm{CO}$ ). The perfusion medium was the same except that $20 . \mathrm{mm} \mathrm{NaHCO}_{3}$ replaced an equimolar amount of $\mathrm{NaCl}$.

The kinetics of the dim flash response were evaluated from the average of responses whose amplitude was less than $0.2 r_{\max }$. The amplitude of the single-photon response was estimated by dividing the peak ensemble variance of a series of responses to dim flashes of fixed strength by the amplitude of the average response. The decay of the dim flash response $\left(T_{r}\right)$ was found from an exponential fit to the falling phase beginning at 0.7 peak amplitude and continuing to baseline. The integration time $\left(T_{i}\right)$ was estimated from the time integral of the flash response divided by the peak amplitude. Because the kinetics of the rod's responses change with increasing flash strength, $t_{p}$ (the time to peak) and $T_{i}$ were evaluated from (1) the dim flash response and (2) the half-maximal response. When a half-maximal response was not recorded, $T_{i}$ and $t_{p}$ were found by interpolation from responses ranging from 0.4 to $0.6 r_{\max }$ in amplitude. Rod responses recorded from nontransgenic mice were similar to those described in Raport et al. (1994). No systematic differences in rod behavior were detected over the developmental period 3-17 weeks postnatal.

\section{Results}

\section{Q344ter and wild-type rhodopsin transgenes}

In earlier work we identified a family with autosomal dominant RP in which affected members carry one copy of a rhodopsin gene that contains a termination codon at position 344 , thereby removing the last five amino acids of the encoded protein (Sung et al., 1991a). Among the 48 rhodopsin mutations identified to date in patients with autosomal dominant RP, eight map to this region of the rhodopsin gene (Fig. 1). Given their close proximity, it seems likely that all of these carboxy-terminal mutations share the same biochemical defect(s). The Q344ter mutant was chosen for further study because we reasoned that a deletion would be more likely than a point mutation to cause a severe biochemical defect, and, as described below, using a deletion mutant allowed us to obtain antibodies that specifically recognize either wild-type or mutant rhodopsins.

Transgenes were constructed from a mouse rhodopsin gene that had been isolated from a size-fractionated BamHI complete digest genomic library of BALB/c liver DNA (Zack et al., 1991). The mouse rather than the human rhodopsin gene was used in these experiments to avoid any possible anomalies that might arise from the presence of the human protein in the mouse retina. Mouse and human rhodopsin are $94 \%$ identical at the amino acid level, and are identical over the carboxy-terminal 11 residues (Nathans and Hogness, 1984; Baehr et al., 1988). One transgene construct was engineered to carry both the Q344ter mutation and a BamHI site at codons 345-347 (Fig. 2). A wildtype control construct differed from the endogenous rhodopsin gene only by the presence of a HhaI site at codons 346-347. The engineered restriction sites allow the transgenes to be iden- 

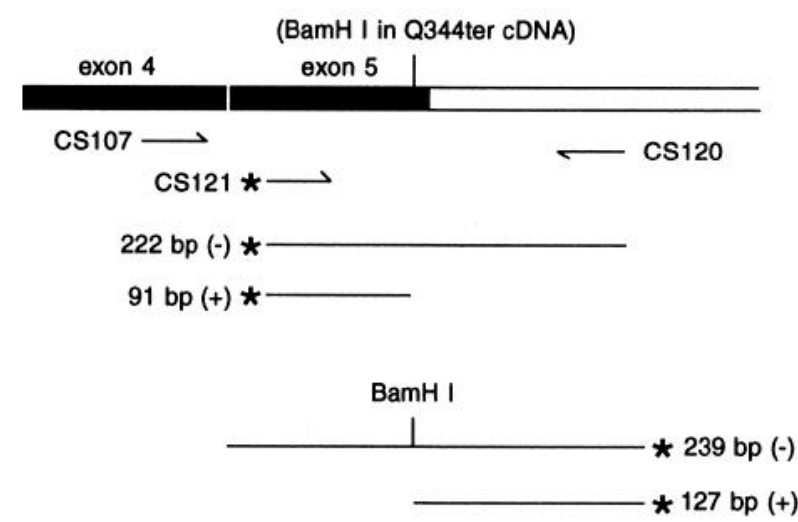

Figure 4. Method for quantitation of the ratio of transcripts derived from the endogenous rhodopsin gene and the rhodopsin transgene. Left, PCR primers CS107 and CS120 in the fourth and fifth exons, respectively, were used for PCR amplification on first-strand cDNA synthesized from total retina RNA. 5'-End-labeled nested primer CS121 was used to prime a single round of DNA synthesis using the PCR product as template. The resulting radiolabeled double-stranded DNA fragment was cleaved with BamHI to generate a 91 bp product derived from the Q344ter transgene, and an uncleaved 222 bp product derived from the endogenous rhodopsin gene. A partially overlapping ${ }^{32} \mathrm{P} 5$ '-end-labeled $239 \mathrm{bp}$ fragment derived from the Q344ter transgene construct was added to each sample to monitor restriction digestion. ${ }^{*}$ indicates ${ }^{32} \mathrm{P}$ 5 ' end label. Right, Examples of reaction products from different Q344ter transgenic mice (lanes $2-4$ ) incubated either with $(+)$ and without $(-)$ BamHI and resolved by denaturing polyacrylamide gel electrophoresis. Lane 1, 239 bp control fragment; lane 2, Q344ter-9 transgenic at P20; lane 3, Q344ter-9 transgenic at P23; lane 4, a derivative of Q344ter-9 with increased transgene expression at P13.

tified in PCR products derived from genomic DNA, and also permit an accurate determination of the ratio of endogenous to transgene-derived RNA by a reverse transcription/PCR assay. Each transgene consisted of an $11 \mathrm{~kb}$ BamHI fragment that includes the entire rhodopsin coding region, $4.5 \mathrm{~kb}$ of 5 ' flanking DNA, and $1.3 \mathrm{~kb}$ of $3^{\prime}$ flanking DNA. This fragment encompasses those sequences that had previously been shown to direct high-level expression of a linked $\beta$-galactosidase reporter to rod photoreceptors in transgenic mice (Lem et al., 1991).

\section{Natural history of retinal degeneration in Q344ter and wild- type rhodopsin transgenic mice}

As summarized in Table 1, three and four independent lines were obtained that carry, respectively, the Q344ter and the wildtype rhodopsin transgenes. For each line, the appearance of the retina was monitored by examining conventional histologic preparations obtained from transgenic animals at different postnatal ages. Among both the Q344ter and wild-type transgenic lines, the transgenic animals showed a progressive degeneration of the photoreceptor layer (Fig. 3), reminiscent of that seen in human RP and in the naturally occurring mouse models of RP, $r d$ and $r d s$ (Sanyal et al., 1980; LaVail, 1981; Heckenlively, 1988). In some lines, anomalous thinning of the outer nuclear layer (that region of the retina containing the more proximal part of the photoreceptor cell bodies) could be seen as early as postnatal day 10. Among different transgenic lines the time course of the degeneration varied from several weeks to several months. However, within a given transgenic line, animal-toanimal variation in the time course of degeneration was less than a factor of 2 . For a single animal, the two eyes invariably

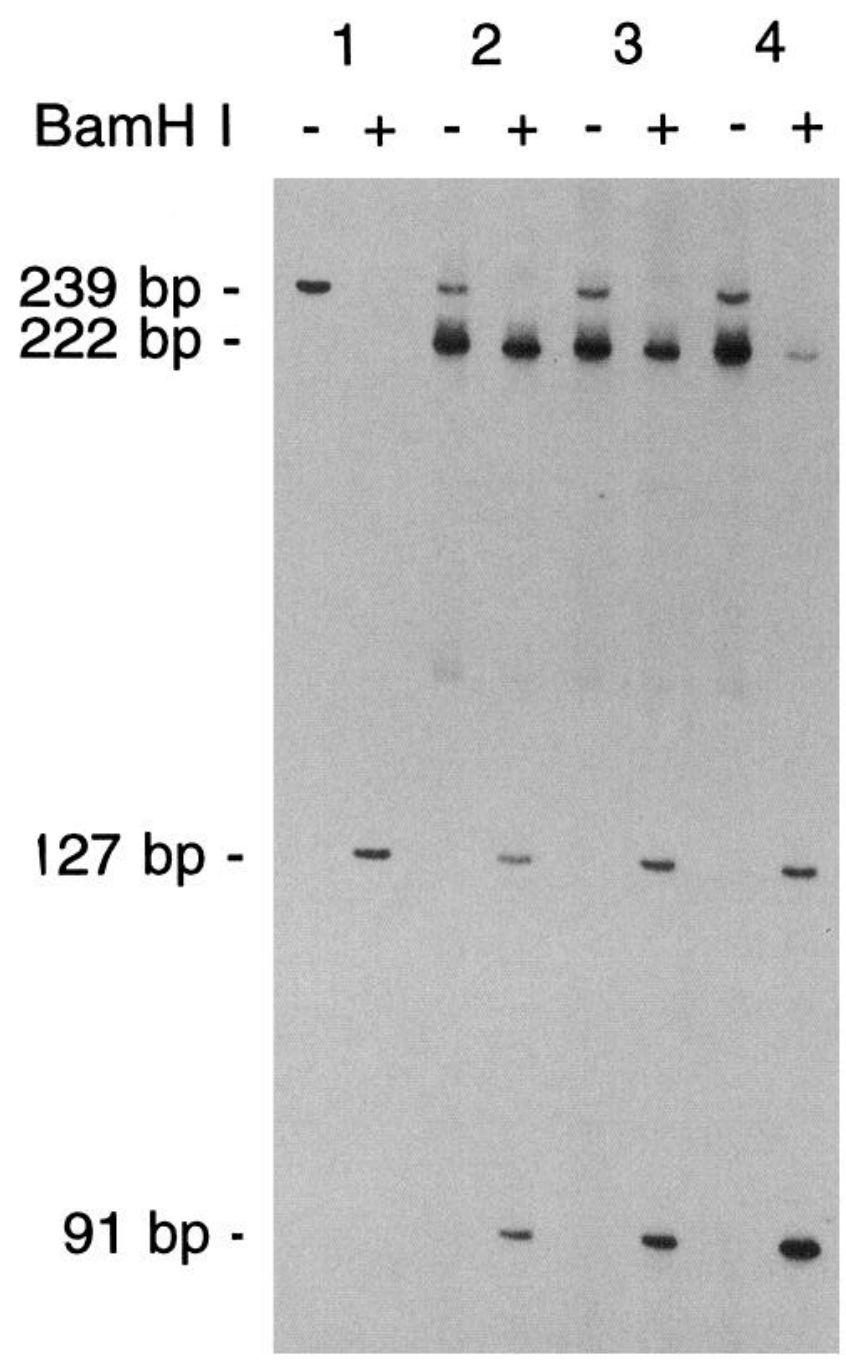

showed the same extent of degeneration and the same level and pattern of transgene expression as determined by immunostaining with antibodies specific for the transgene product (see below). None of the nontransgenic littermates showed a retinal degeneration.

To determine whether a correlation existed between the time course of the retinal degeneration and the level of transgene expression, animals were sacrificed at various ages, and one retina was used for histologic analysis and the other retina used to determine the ratio of RNA transcripts synthesized from the transgene and from the endogenous rhodopsin gene. The ratio of RNA transcripts was determined by reverse transcribing total retina RNA with random sequence primers, PCR amplifying a segment of the cDNA encompassing part of exon 4 and the entire coding region of exon 5 , and priming a single round of DNA synthesis on the PCR product using a nested primer radiolabeled at its $5^{\prime}$ end. Because the radiolabeled products are generated in a single round of DNA synthesis, this strategy avoids problems associated with the formation of heteroduplex DNA during multiple cycles of annealing and synthesis. Under the PCR conditions used the corresponding genomic DNA region does not amplify due to the large size of intron 4 . The 222 bp end-labeled extension product, representing a mixture of endogenous and transgene sequences, was cleaved with either 


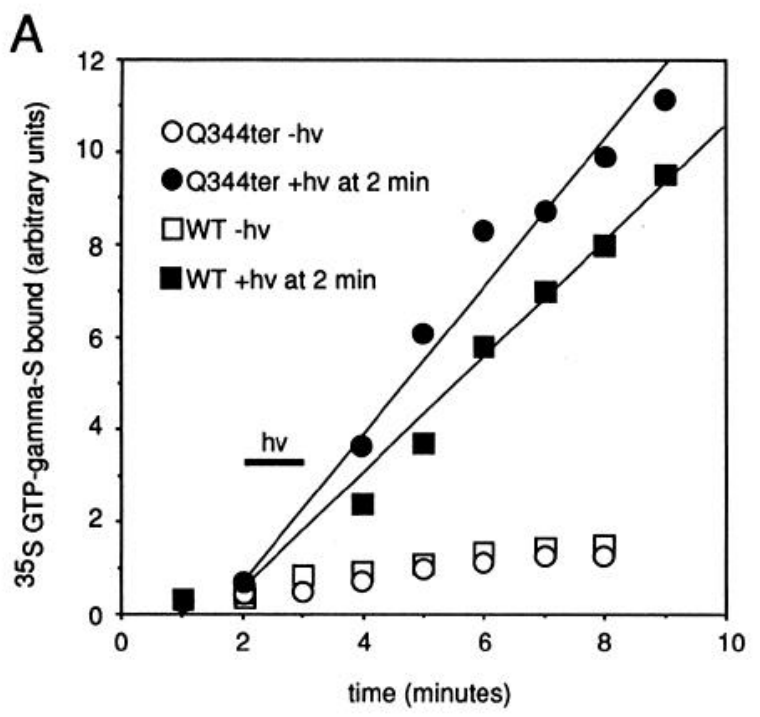

B

\section{wild type Q344ter}

\section{rhodopsin kinase} light $80-$ $49.5-$ $32.5-$ $27.5-$ $18.5-$
BamHI for the Q344ter transgenic mice or Hhal for the wildtype transgenic mice, and resolved on a denaturing polyacrylamide gel. In each case the product derived from the rhodopsin transgene is cleaved at the engineered restriction site to yield a fragment of 91 bases, whereas the product derived from the endogenous rhodopsin gene lacks the restriction site and therefore remains as a fragment of 222 bases. To control for the possibility of incomplete restriction enzyme digestion, a second end-labeled fragment of $239 \mathrm{bp}$, generated by extension on the cloned transgene template using a different end-labeled primer, was added to the sample prior to addition of the restriction enzyme. Figure 4 shows an example of the use of this assay with three Q344ter samples.

The reverse transcriptase/PCR analysis reveals significant variation in transgene expression levels between lines and a roughly consistent level of transgene expression within a line (Table 1). Some of the variation among animals within a line could reflect cell-to-cell variation in the level of transgene expression and a consequent cell-to-cell variation in the time course of cell death. Such variation would have the effect of underestimating the average level of transgene expression in the retina, and would predict that the most accurate measure of transgene expression would be obtained from animals sacrificed prior to the onset of the degeneration. The analysis of retinal degeneration and transgene expression levels shows that expression of the Q344ter transgene at a level comparable to that of the endogenous rhodopsin gene can produce photoreceptor degeneration within several weeks of birth (Table 1). Line Q344ter-9, which has the lowest level of Q344ter transgene expression, exhibits a significantly slower degeneration. Interestingly, expression of the wild-type rhodopsin transgene at levels severalfold higher than that of the endogenous rhodopsin gene also produces photoreceptor degeneration. One wild-type transgenic line (WT-29) expressed the transgene at low level and showed little or no photoreceptor degeneration during the first several months of life. These data suggest that the level of rhodopsin gene expression is tightly regulated in the normal retina and that an increase in the level of rhodopsin synthesis is detrimental to the photoreceptor cell. Because expression of either mutant or wild-type rhodopsin transgenes causes a progressive loss of photoreceptors, we cannot determine from these experiments whether the Q344ter mutation per se is deleterious to the retina.

\section{Q344ter resembles wild-type rhodopsin in its interaction with phototransduction enzymes}

In earlier work we compared several properties of wild-type human rhodopsin and the Q344ter mutant following transfection of their corresponding cDNA clones into a human embryonic kidney cell line (293S; Sung et al., 1991b). Those experiments showed that in both cases the apoproteins accumulated in the plasma membrane to a level of several million molecules per cell and that both proteins could efficiently bind 11-cis retinal in vitro to form a photolabile visual pigment with the native absorption spectrum. While these experiments indicate that the Q344ter mutant is able to fold correctly and travel through the ER-Golgi-plasma membrane pathway, they left open the possibility that the Q344ter mutant might possess a functional defect in signal transduction or some other photoreceptor-specific function.

In the photoreceptor, three proteins are known to interact with rhodopsin: the photoreceptor G-protein transducin, rhodopsin kinase, and arrestin. In each case the interaction is spe- 

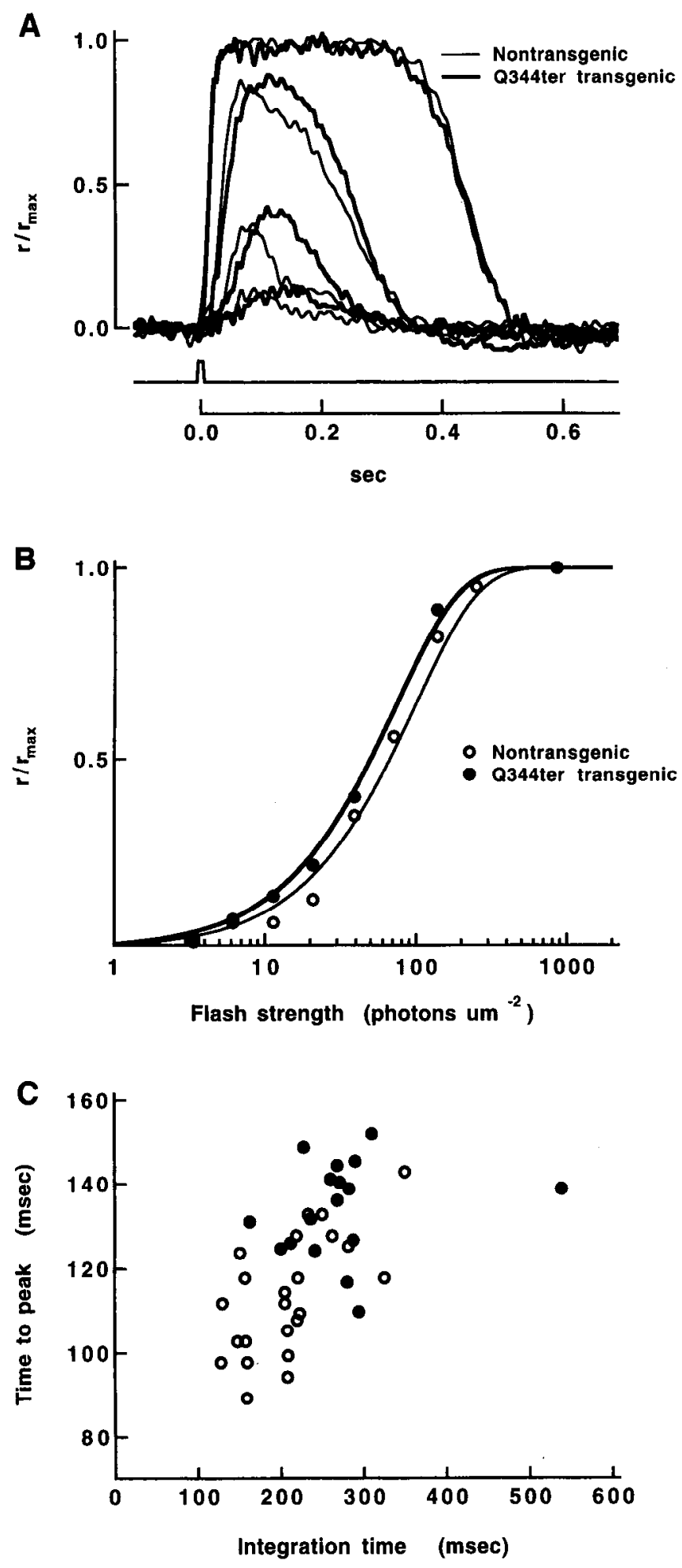

Figure 6. Light responses of single rods from Q344ter-9 transgenic and nontransgenic control retinas. $A$, Normalized, averaged responses from a representative nontransgenic control rod (light traces) and a Q344ter-9 transgenic rod (dark traces) to flashes of increasing strength. Flash monitor output is shown in the lowermost trace. For the control rod the maximal responsc was $5.2 \mathrm{pA}$, and for the $\mathrm{Q} 344$ ter-9 transgenic rod it was $8.1 \mathrm{pA}$. Membrane current recordings were low-pass filtered at $30 \mathrm{~Hz}$. The delay introduced by low-pass filtering was corrected by shifting each response curve $17 \mathrm{msec}$ along the horizontal axis. $B$, Relation between peak response amplitude and flash strength for the rods shown in $A$ : nontransgenic control (open symbols) and Q344ter-9 transgenic (solid symbols). Continuous lines show fits with exponential sat- cific for photoactivated rhodopsin. In the first stage of the phototransduction cascade, rhodopsin catalyzes the exchange of bound GDP for free GTP by transducin (Fung and Stryer, 1980), and in the first step in terminating this activity, rhodopsin serves as the substrate for phosphorylation by rhodopsin kinase (Kuhn et al., 1984). Arrestin is a soluble protein that completes the termination reaction by binding to photoactivated and phosphorylated rhodopsin to sterically block access to transducin (Wilden et al., 1986).

To test the ability of Q344ter to activate transducin in a lightdependent manner, a filter binding assay was used to measure the activity of detergent-solubilized membranes containing either Q344ter or wild-type recombinant human rhodopsin in catalyzing the binding of ${ }^{35} \mathrm{~S}$ GTP- $\gamma-\mathrm{S}$ to purified bovine transducin. As shown in Figure $5 A$, both wild-type and Q344ter rhodopsins catalyzed the binding of GTP- $\gamma-\mathrm{S}$ with similar efficiencies and in a light-dependent manner. Similar results were obtained in three independent experiments. To examine the signal termination reaction, detergent-solubilized membranes containing $\gamma-{ }^{32} \mathrm{P}$-ATP and either Q344ter or wild-type rhodopsin were incubated for various times either in darkness or in the light and either with or without rhodopsin kinase purified from bovine rod outer segments. Both wild-type and Q344ter rhodopsins were phosphorylated with similar efficiencies in a light- and rhodopsin kinase-dependent manner. Figure $5 B$ shows the reaction products following immunoprecipitation using a monoclonal antibody (mAb) that recognizes rhodopsin's amino terminus (B6-30; Adamus et al., 1988). Similar efficiencies of phosphate incorporation were observed after incubation for 7 , 10 , or $30 \mathrm{~min}$ at room temperature (data not shown). These data are in agreement with current models of the interaction between bovine rhodopsin, transducin, and rhodopsin kinase based upon partial proteolysis of bovine rhodopsin and competition with synthetic peptides derived from the rhodopsin sequence (Konig et al., 1989; Kelleher and Johnson, 1990; Palczewski et al., 1991). We have not measured the binding of arrestin to either wild-type or mutant rhodopsins.

\section{Phototransduction in transgenic mice expressing Q344ter rhodopsin}

Although the biochemical experiments described above show that transducin activation and rhodopsin phosphorylation are not grossly affected by the Q344ter mutation, it remained to be determined whether or not the mutant protein perturbed the photoresponse in vivo. We therefore used suction electrode recording to measure the light-induced change in the membrane current of single rod outer segments from the retinas of Q344ter and nontransgenic control mice. The Q344ter- 9 transgenic line was chosen for these experiments because it degenerates slowly, suggesting that rod function might be reliably measured in young animals. In each case, prior to enucleating an eye for recording,

uration functions $\left[r / r_{\max }=1-\exp (-k i)\right.$ where $k$ is a constant that is inversely proportional to the sensitivity of the cell and $i$ is flash strength (Lamb et al., 1981)] with half-maximal responses to light of $500 \mathrm{~nm}$ at 67 (nontransgenic control, thin line) and 50 (Q344ter transgenic, thick line) photons $\mu \mathrm{m}^{-2}$, respectively. $C$. Scatter plot of the relation between integration time and time to peak for the dim flash responses of nontransgenic control rods (open symbols, $n=23$ ) and Q344ter-9 transgenic rods (solid symbols, $n=17$ ). Control rods have on average shorter $t_{p}$ and $T_{i}$. 
HOOC- APAVQSTET 1D4 HOOC. STETKSATAS JH778

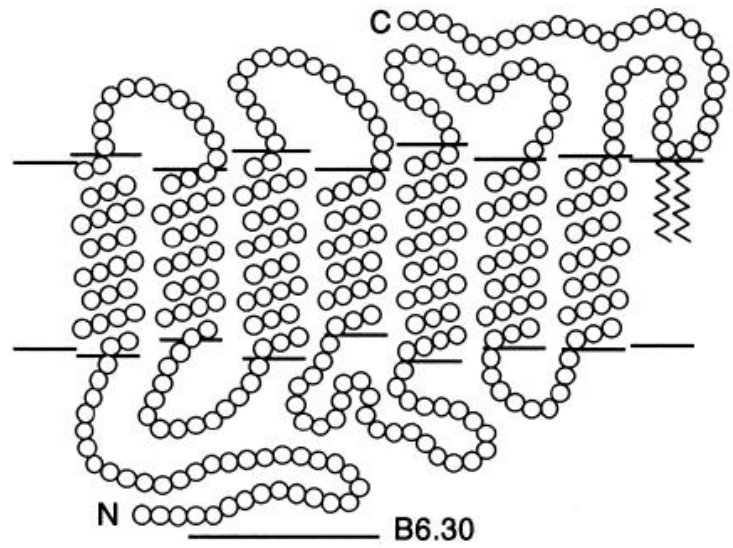

WT
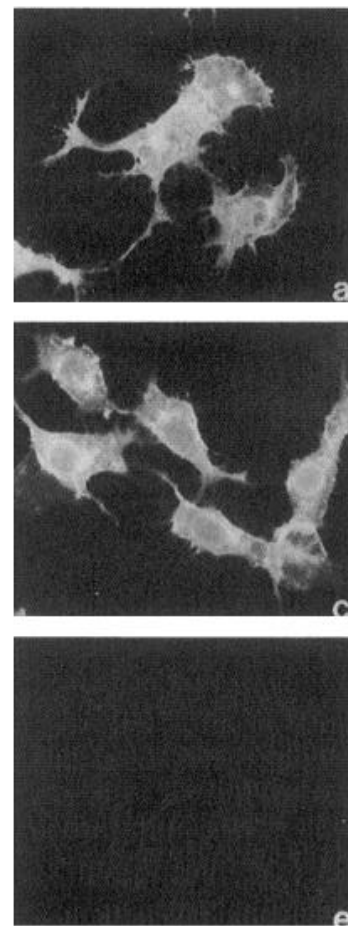

Q344ter

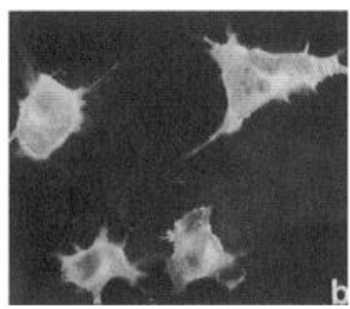

B6-30

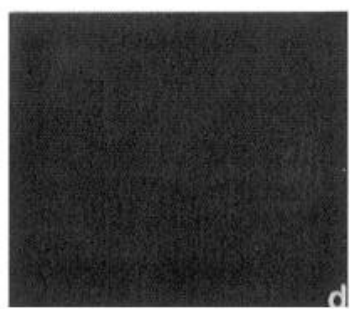

ID4

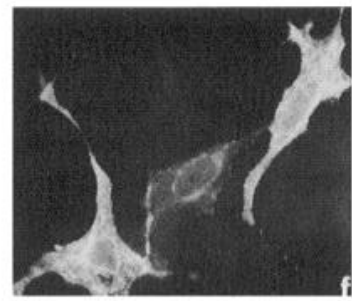

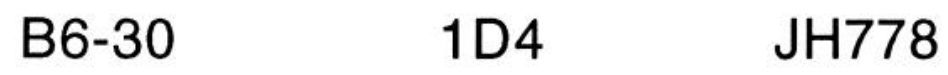

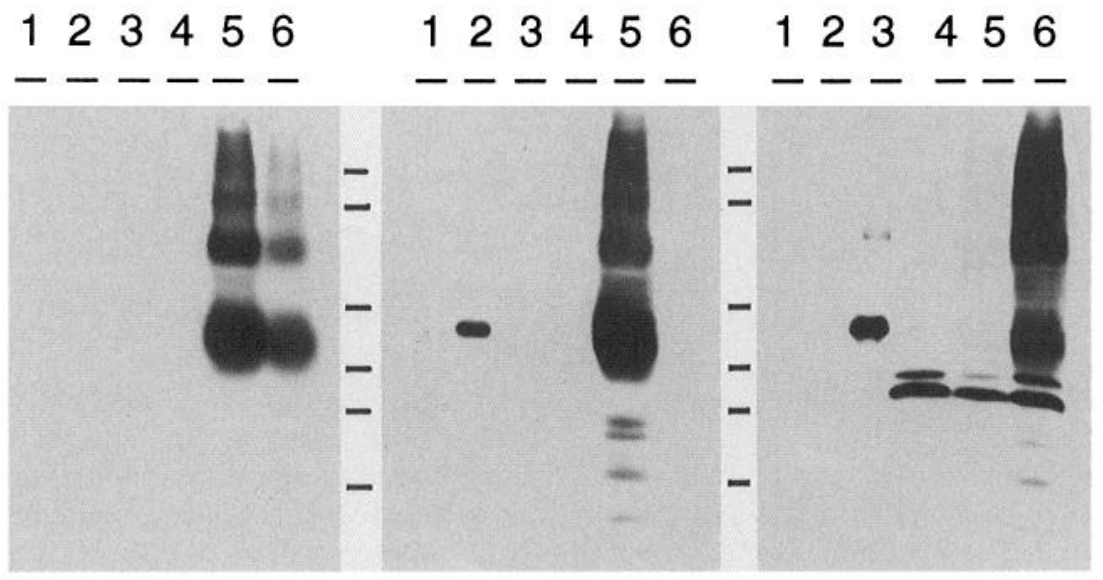

Figure 7. Characterization of antibodies specific for wild-type and Q344ter rhodopsins. Left, Transmembrane model of rhodopsin showing the locations of epitopes recognized by anti-rhodopsin antibodies. B6-30 and 1D4 are mouse monoclonal antibodies that react with residues 3-14 and 340-348, respectively (Adamus et al., 1988; Hodges et al., 1988); the sequence of the 1D4 epitope is shown. JH778 is a rabbit antiserum generated by immunizing with the indicated peptide conjugated to BSA. Right, Specificity of anti-rhodopsin antibodies determined by immunostaining transiently transfected cells. cDNA encoding either wild-type rhodopsin $(a, c, e)$ or Q344ter $(b, d, f)$ inserted into expression vector pCIS was transiently transfected into 293S cells. Sixteen hours after transfection, the cells were methanol fixed and immunostained either with B6-30 $(a, b), 1 \mathrm{D} 4(c, d)$, or $\mathrm{JH} 778(e, f)$, followed by fluorescein-conjugated goat anti-mouse IgG (B6-30, 1D4) or rhodamine-conjugated goat anti-rabbit IgG (JH778). Bottom, Specificity of anti-rhodopsin antibodies determined by Western blotting. Lane $1,1 \mu \mathrm{g}$ of affinity-purified $E$. coli maltose binding protein (MBP); lane 2, $1 \mu \mathrm{g}$ of affinity-purified MBP fusion protein carrying the carboxy-terminal 27 amino acids of wild-type rhodopsin; lane 3, $1 \mu \mathrm{g}$ of affinity-purified MBP fusion protein carrying the carboxy-terminal 22 amino acids of Q344ter; lane 4, membranes from nontransfected 293S cells; lane 5, membranes from a 293S cell line expressing wild-type human rhodopsin; lane 6, membranes from a 293S cell line expressing Q344ter rhodopsin. Lanes 4-6 each contain $25 \mu \mathrm{g}$ of total protein. Recombinant opsin is heterogeneously glycosylated and aggregates to form multimers upon denaturation in SDS sample buffer. 
Table 2. Transduction parameters in Q344ter transgenic and nontransgenic rods

\begin{tabular}{lccccc} 
Parameter & $\begin{array}{l}\text { Q344ter } \\
\text { transgenic }\end{array}$ & $n$ & Nontransgenic & $n$ & $\begin{array}{l}\text { of difference } \\
\text { of }\end{array}$ \\
\hline$r_{\max }(\mathrm{pA})$ & $5.9 \pm 2.3$ & 18 & $6.3 \pm 2.4$ & 23 & \\
$i_{o}\left(\mathrm{photons} \mu \mathrm{m}^{-2}\right)$ & $40 \pm 14$ & 17 & $50 \pm 13$ & 23 & $p<0.02$ \\
$S_{f}\left(\mathrm{pA} \mu \mathrm{m}^{2}\right.$ photon $\left.^{-1}\right)$ & $0.114 \pm 0.091$ & 18 & $0.068 \pm 0.031$ & 23 & $p<0.03$ \\
Single photon response & & & & & \\
$\quad$ Amplitude (pA) & $0.4 \pm 0.2$ & 13 & $0.4 \pm 0.1$ & 14 & \\
$\quad$ Amplitude/ $r_{\text {max }}$ & $0.07 \pm 0.02$ & 13 & $0.06 \pm 0.02$ & 13 & \\
$t_{p} \quad$ & & & & \\
$\quad$ Dim flash response (msec) & $134 \pm 12$ & 17 & $114 \pm 14$ & 23 & $p<0.00002$ \\
$\quad$ Half-maximal response (msec) & $123 \pm 16$ & 11 & $99 \pm 11$ & 18 & $p<0.00002$ \\
$T_{i} \quad$ & & & & & \\
$\quad$ Dim flash response (msec) & $267 \pm 80$ & 18 & $209 \pm 58$ & 23 & $p<0.01$ \\
$\quad$ Half-maximal response (msec) & $283 \pm 66$ & 15 & $238 \pm 74$ & 22 & $p<0.06$ \\
$T_{r}$ Dim flash response (msec) & $244 \pm 302$ & 16 & $166 \pm 85$ & 9 & \\
$I_{o}$ (photons $\mu \mathrm{m}^{-2}$ sec ${ }^{-1}$ ) & 227 & 1 & $318 \pm 101$ & 5 &
\end{tabular}

Collected results are from six Q344ter-9 transgenic and six nontransgenic mice. All parameter values are expressed as mean $\pm \mathrm{SD}$. $n$, numbers of rods recorded; $r_{\max }$ is the amplitude of the saturating response; $i_{0}$ is the flash strength that gave a half-maximal response; $S_{f}$ is flash sensitivity, equal to the amplitude of the dim flash response divided by the flash strength; $T_{i}$ is the integration time; $t_{p}$ is the time to peak; $T_{r}$ is the exponential decay constant for the recovery of the dim flash response; $I_{0}$ is the background intensity that reduced the flash sensitivity to half the value in darkness.

the contralateral eye was removed and shown to contain Q344ter opsin in over $90 \%$ of the rods as determined by immunostaining with an antibody specific for Q344ter (see below).

Transgenic rods expressing Q344ter rhodopsin generated light responses that closely resembled those of rods from nontransgenic mice. Figure $6 A$ shows families of responses to flashes of increasing strength from a representative nontransgenic rod (light traces) and a Q344ter transgenic rod (dark traces). Although the two families are broadly similar, the Q344ter transgenic rod's responses to dim flashes reached its peak slightly later than did the nontransgenic rod's responses. This difference was characteristic of the populations of transgenic and nontransgenic rods, as illustrated in the scatter plot of Figure $6 C$, which shows values of time to peak and integration time (mean response duration) from nontransgenic (open circles) and Q344ter transgenic (solid circles) rods. Values for these and several other parameters of the light response are presented in Table 2 . Figure $6 B$ is a semi$\log$ plot of the relationship between the peak response amplitude and the flash strength for the cells in Figure $6 \mathrm{~A}$. The smooth curves are saturating exponentials (Lamb et al., 1981) whose positions on the abscissa differ slightly. The flash strength $\left(i_{o}\right)$ at $500 \mathrm{~nm}$ that gave a response of half saturating amplitude was 67 photons $\mu \mathrm{m}^{-2}$ for the nontransgenic rod and 50 photons $\mu \mathrm{m}^{-2}$ for the Q344ter transgenic rod. There was a similar difference in the population mean valucs for $i_{o}$, and, consistent with this, the Q344ter transgenic rods had a slightly higher mean sensitivity to dim flashes (Table 2). The amplitudes of single photon and saturating responses and the time constants for the recovery of the flash response were not significantly different for the two types of rods. One Q344ter transgenic rod tested was found to adapt normally in background light. The steady intensity $\left(I_{o}\right)$ at $500 \mathrm{~nm}$ required to reduce flash sensitivity to half the dark-adapted value was 227 photons $\mu \mathrm{m}^{-2} \mathrm{sec}^{-1}$ for the one Q344ter transgenic rod tested, compared to a value of 318 \pm 101 photons $\mu \mathrm{m}^{-2} \mathrm{sec}^{-1}$ (mean $\pm \mathrm{SD}, n=5$ ) in nontransgenic rods. In both types of rods the response to an incremental flash accelerated in background light (Tamura et al., 1989). The spectral sensitivity of onc transgenic and three control rods were measured and found to peak near $500 \mathrm{~nm}$. The general conclusion is that although the transgenic rods behaved nearly normally, their responses were on average slightly slower and more sensitive than those of control rods.

\section{Immunolocalization of Q344ter and endogenous rhodopsin}

As mentioned above, one motivation in choosing the Q344ter mutant for further study was the possibility that antibodies specific for either the mutant or the wild-type protein could be obtained, thus permitting the simultaneous visualization of the two proteins in transgenic retinas. In previous work, Hodges et al. (1988) identified a mAb, 1D4, which recognizes the carboxyterminal nine amino acids of bovine and other mammalian rhodopsins (Fig. 7, left). 1D4 recognizes wild-type but not Q344ter human rhodopsin as determined by Western blotting of the recombinant opsins produced in $293 \mathrm{~S}$ cells (Fig. 7, bottom, lanes 4-6) and $E$. coli-derived fusion proteins carrying the carboxy-terminal 27 or 22 amino acids of wild-type or Q344ter opsins, respectively (Fig. 7, bottom, lanes 1-3). The specificity of 1D4 for wild-type rhodopsin is also seen by immunofluorescent staining of $293 \mathrm{~S}$ cells transiently transfected with either wild-type or Q344ter cDNA clones (Fig. 7, right). Parallel immunostaining reactions carricd out with $\mathrm{mAb}$ B6-30, which binds an epitope near the amino-terminus, show that this antibody recognizes both wild-type and Q344ter rhodopsins as expected.

Peptide competition experiments have indicated that a free carboxy-terminus is essential for high affinity binding by 1D4 (Hodges et al., 1988). We reasoned, therefore, that antibodies specific for the Q344ter protein could be generated by immunization with a synthetic peptide corresponding to the carboxyterminus of Q344ter. A 10 amino acid peptide corresponding to residues 334-343 of mouse rhodopsin (which differs from the human rhodopsin sequence only by the replacement of valine ${ }^{337}$ 

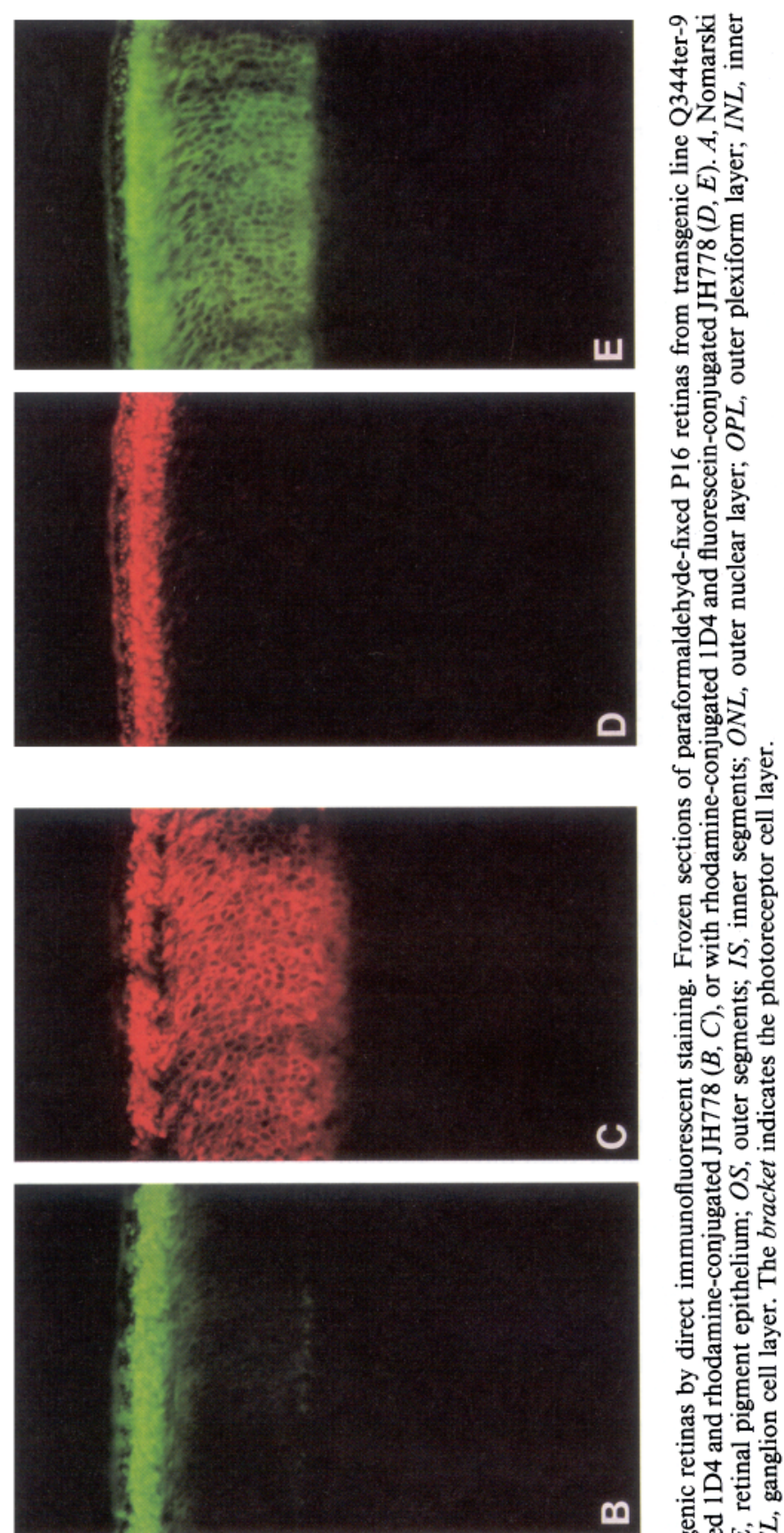

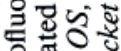

照证

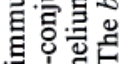

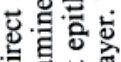

害

주욜

㩆器

든

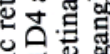

势

墕

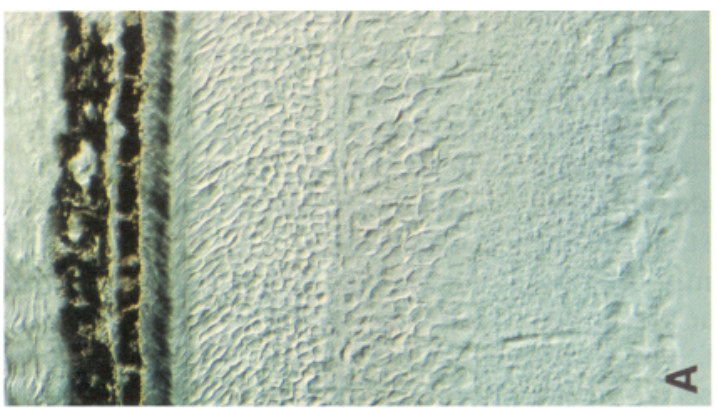

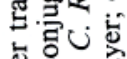

论证

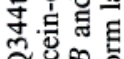

人。्.

엉

造的

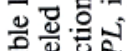

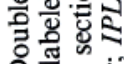

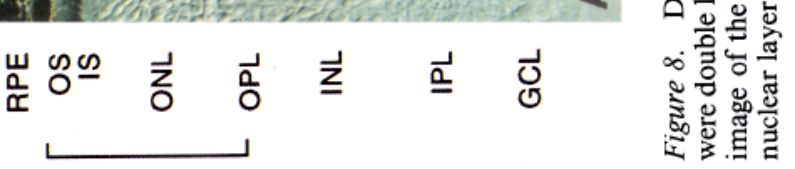



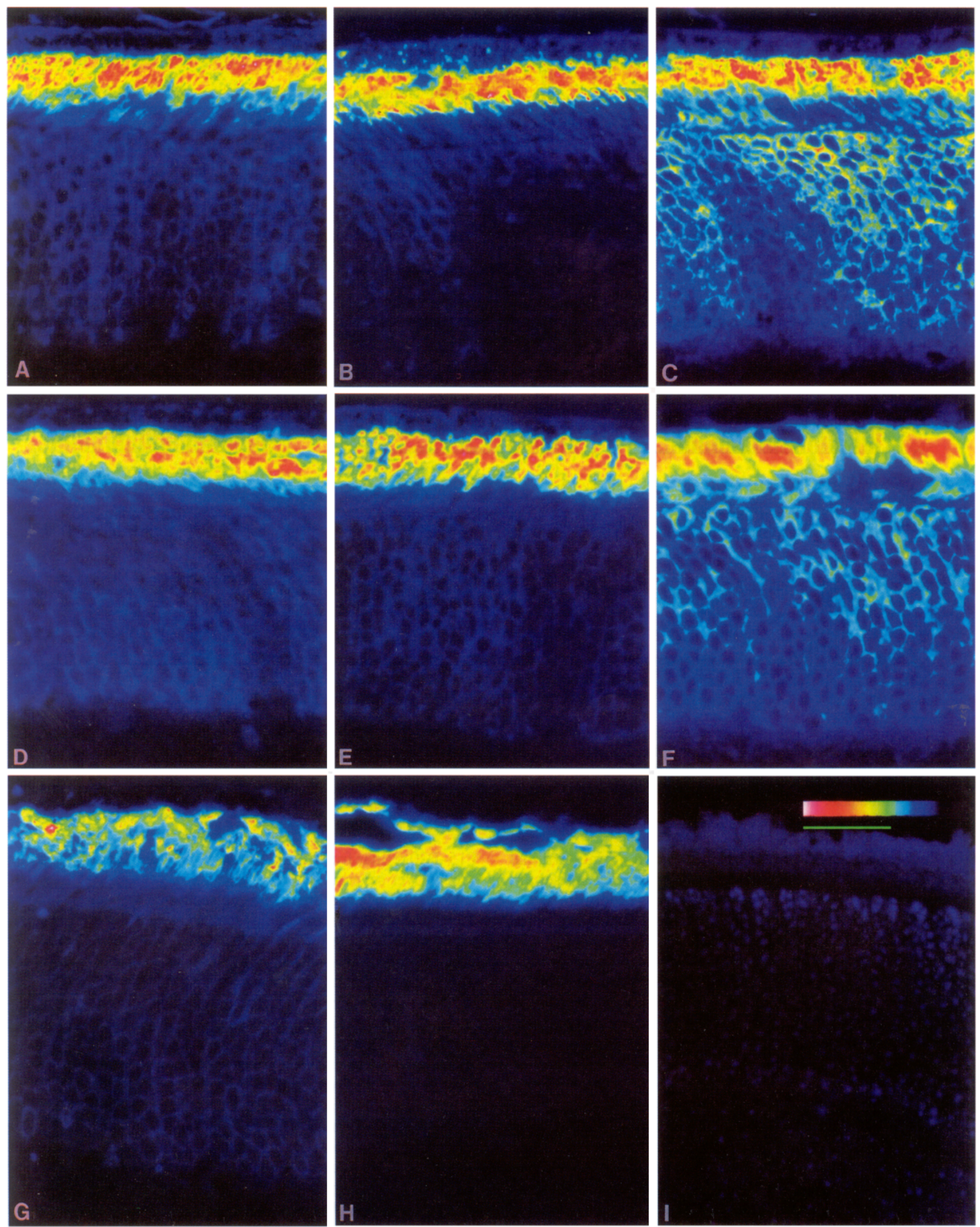

Figure 9. Direct immunofluorescent staining recorded by laser scanning confocal microscopy. Frozen sections of paraformaldehyde-fixed retinas from transgenic line Q344ter-9 at P16 $(A-F)$ or from a nontransgenic mouse at P18 $(G-I)$. Retinas were stained by direct immunofluorescence with rhodamine-conjugated B6-30 $(A), 1 \mathrm{D} 4(B)$, and JH778 $(C)$, or with fluorescein-conjugated B6-30 $(D, G), 1 \mathrm{D} 4(E, H)$, and JH778 $(F, I)$. Images were recorded using a photomultiplier detector and are presented in false color with short wavelengths representing low intensity and long wavelengths high intensity. Scale bar, $25 \mu \mathrm{m}$. 

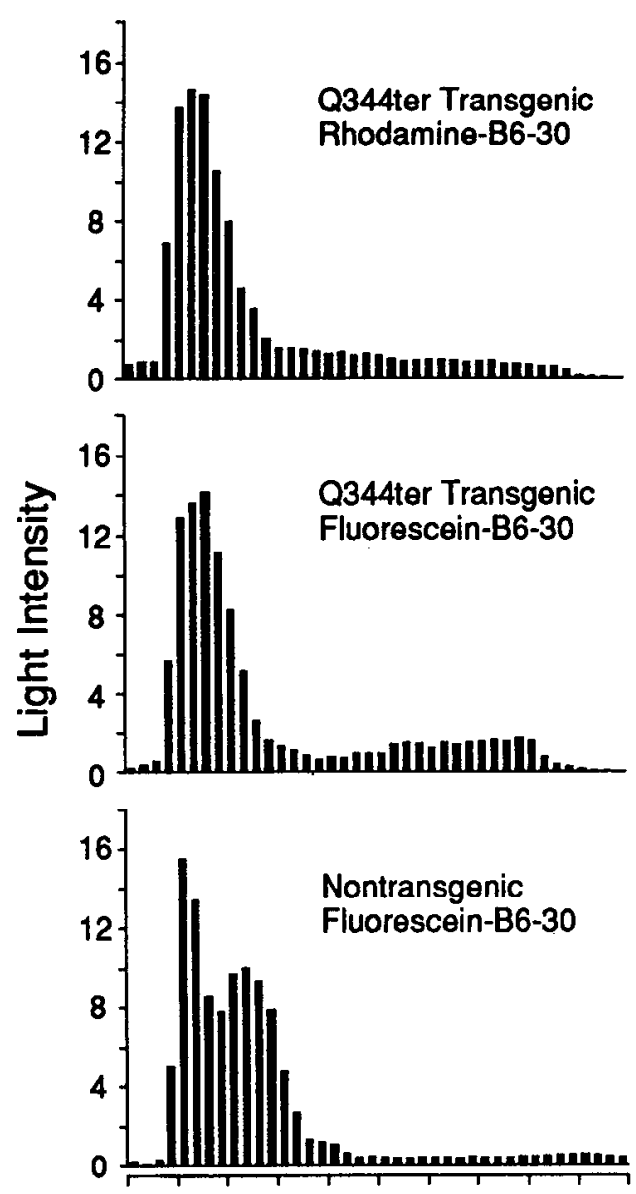
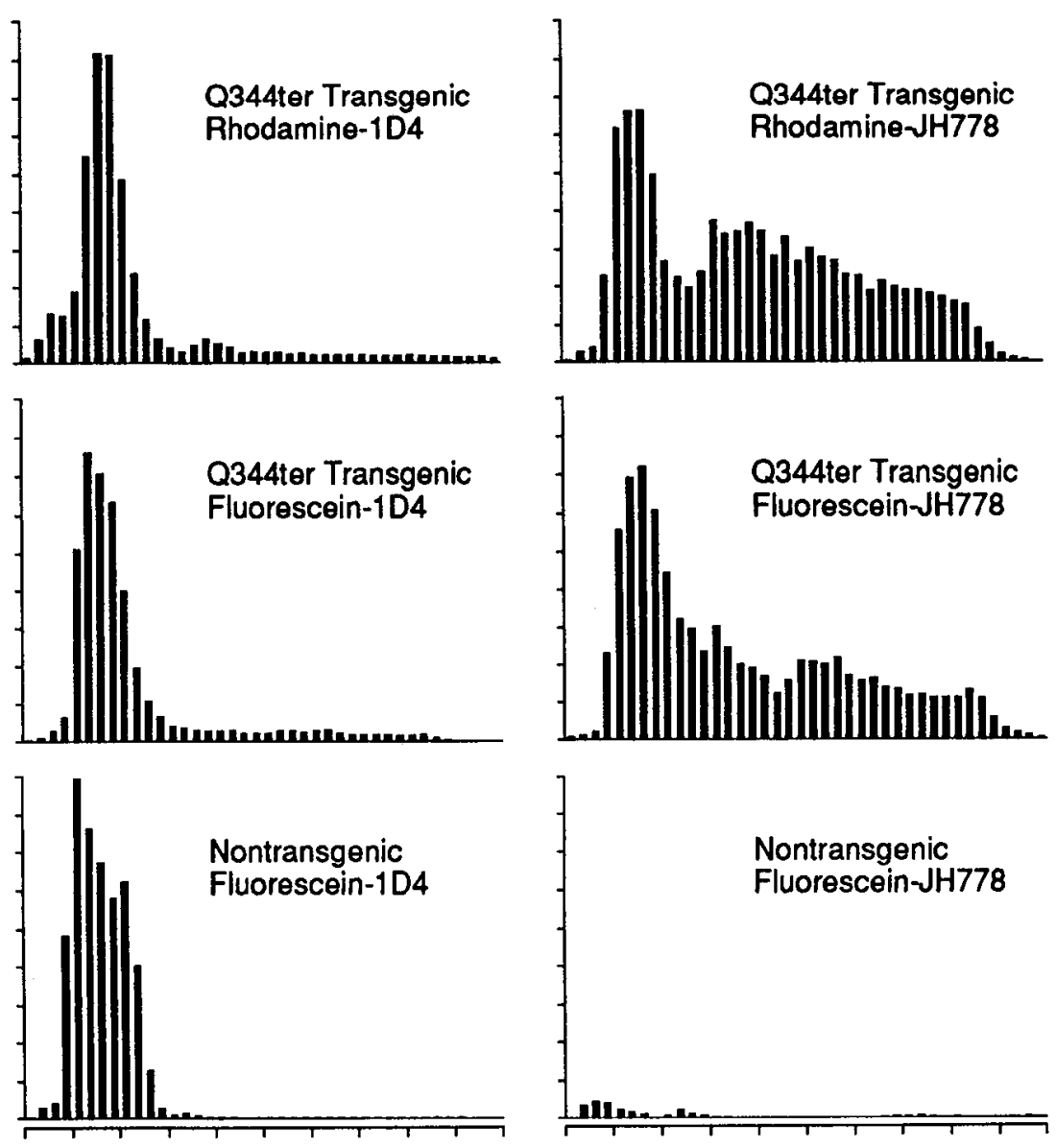

\section{Distance along the Retina}

Figure 10. Quantitative analysis of direct immunofluorescent staining. Laser scanning confocal images were stored digitally and the light intensity calculated for a series of adjacent rectangular areas $2.5 \mu \mathrm{m} \times 30 \mu \mathrm{m}$ oriented with their long axes parallel to the plane of the retina, and which together span beyond the width of the photoreceptor layer (i.e., from the inner nuclear layer to the retinal pigment epithelium). For each image, nonspecific background fluorescence was measured over the inner retina and subtracted from the data. The outer segment region is to the left and corresponds to the peak fluorescence; the inner segment is to the right. The marks along the horizontal axis represent intervals of $10 \mu \mathrm{m}$.

with alanine) was cross-linked to BSA via an amino-terminal cysteine and used for immunization. The resulting antiserum, JH778, recognizes Q344ter but not wild-type rhodopsin as determined by Western blotting and by immunostaining of transfected cells as described above (Fig. 7).

In preliminary experiments using indirect immunofluorescence to stain Q344ter transgenic retinas, we observed significant JH778 immunostaining in both the cell bodies and outer segments from P15-P25 retinas. No immunostaining was observed with nontransgenic retinas. By contrast, 1D4 immunostaining of Q344ter transgenic retinas was barely detectable in the photoreceptor cell bodies and was high in the outer segments, a pattern indistinguishable from that obtained with nontransgenic retinas. This differential pattern of immunolocalization was observed in each of the three Q344ter transgenic lines. To assess quantitatively this difference in immunostaining patterns, we sought to avoid nonlinearities that might result from the multistep indirect immunofluorescent method by carrying out a scrics of mcasurements using direct immunofluorescent staining with both fluorescein conjugation and rhodamine conjugation of 1D4, B6-30, and affinity-purified JH778. To minimize perturbations related to the degenerative process, the immunostaining experiments described below were carried out with
$\mathrm{P} 15-\mathrm{P} 20$ retinas from line $\mathrm{Q} 344$ ter-9, in which the degeneration occurs over several months (Table 1).

In one set of experiments, retina sections were double labeled using either fluorescein-conjugated 1D4 and rhodamine-conjugated JH778 (Fig. 8B,C) or rhodamine-conjugated 1D4 and fluorescein-conjugated JH778 (Fig. $8 D, E$ ). In both cases the distribution of mutant and wild-type protein clearly differ. The cell body staining by $\mathrm{JH} 778$ appears to be confined principally to the plasma membrane as determined by optical sectioning with the confocal laser scanning microscope (data not shown), consistent with the efficient transportation of Q344ter to the plasma membrane of transfected 293S cells (Sung et al., 1991b). Similar results were obtained with each of the other two Q344ter transgenic lines. To quantitate the intensity of immunolabeling at different points in the retina, stained sections were analyzed by confocal laser scanning microscopy using a photomultiplier to measure light intensity. In these experiments we analyzed adjacent sections that had been immunostained with different antibodies, rather than single sections that had been double stained. This protocol avoids inaccuracies in quantitating double-stained sections that arise from the overlap between the rhodamine and fluorescein emission spectra. Except for $\mathrm{JH} 778$ staining of nontransgenic retinas, the images were recorded dig- 
itally with the gain and black level set so that in all cases the point of maximal intensity in the field of view delivered the same number of photons per second to the detector (see Materials and Methods). Figure 9 shows representative examples in which light intensity is represented with a false color scalc.

Each confocal image was digitally stored and then divided into 40 adjacent areas $2.5 \mu \mathrm{m}$ in width that together spanned the photoreceptor layer. Photon fluxes were calculated for each area and plotted as shown in Figure 10 for one representative experiment. From two experiments, the ratio of outer segment to cell body staining intensity in nontransgenic retinas was 80 and 18 for rhodamine-conjugated 1D4 and B6-30, respectively; and 66 and 27 for fluorescein-conjugated 1D4 and B6-30, respectively. For Q344ter transgenic retinas, the ratio of outer segment to cell body staining intensity was 33,15 , and 3 for rhodamine-conjugated $1 \mathrm{D} 4, \mathrm{~B} 6-30$, and $\mathrm{JH} 778$, respectively; and 32,12 , and 4 for fluorescein-conjugated 1D4, B6-30, and $\mathrm{JH} 778$, respectively. For those samples with low levels of cell body staining, the ratios listed above should be considered estimates as the cell body staining was only marginally above background.

The distribution of B6-30 immunostaining resembles a weighted average of the 1D4 and JH778 distributions (Figs. 9, 10 ), and indicates that in the Q344ter-9 transgenic line the mutant opsin is present at a level approximately one-third that of the endogenous opsin. The lack of significant B6-30 staining in the cell body of nontransgenic retinas rules out the possibility that the absence of 1D4 staining in this region is due to selective masking of the carboxy-terminus of wild-type opsin. Interestingly, a small increase in 1D4 immunostaining is seen in the photoreceptor cell bodies of Q344ter transgenic mice compared to nontransgenic control mice (Fig. 10). This could be due to some physiological perturbation related to the begining of the photoreceptor degeneration, or to an interaction between the endogenous and Q344ter rhodopsins. The nontransgenic staining data are in agreement with previous immunoelectron microscopic studies of frog, rat, and human rods that show high levels of opsin in the outer segment plasma membrane and barely detectable levels in the inner segment plasma membrane (Nir and Papermaster, 1983; Nir et al., 1984) and with earlier light microscopic immunostaining experiments of mammalian retinas using a variety of monoclonal antibodies (Hicks and Barstable, 1987; Rohlich et al., 1989). We have not attempted to quantitate the distribution of opsin in those wild-type rhodopsin transgenic lines with significant levels of transgene expression due to the rapid time course of the retinal degeneration in these animals.

\section{Discussion}

The experiments reported here were aimed at determining the nature of the functional defect in one rhodopsin mutant, Q344ter, responsible for autosomal dominant RP. This rhodopsin mutation is one of eight that cluster within the carboxy-terminal 10 amino acids. In earlier work, four of the eight carboxy-terminal mutants were produced by transfection of $293 \mathrm{~S}$ cells, and each was found to resemble the wild type in yield, plasma membrane localization, and ability to efficiently bind 11 -cis retinal (Sung et al., 1991b, 1993). For the Q344ter mutant we report here two additional biochemical similarities to wild-type rhodopsin: in activating transducin in a light-dependent manner, and in serving as a light-dependent substrate for rhodopsin ki- nase. It seems likely that the other mutations in this class, in particular the five point mutations that reside distal to the Q344ter mutation (Fig. 1), will also resemble the wild type in these two properties.

\section{Light responses of single rods}

Recording the light response from single rods with a suction electrode provided a more stringent test of signaling by Q344ter rhodopsin. This method measures the function of the entire phototransduction cascade in an intact cell. Given the comparable levels of Q344ter and endogenous rhodopsin in the transgenic retina, a significant change in the function of the mutant protein would be likely to cause a significant change in the time course and/or size of the response to light. Similarly, inhibition or facilitation of the function of wild-type rhodopsin by Q344ter rhodopsin would also be expected to distort the light response.

Overall, the light responses of Q344ter transgenic and control nontransgenic rods were very similar, although Q344ter rods were slightly slower and more sensitive than nontransgenic rods. The small difference in phototransduction between Q344ter and nontransgenic rods might be explained in either of two ways. One possibility is a global perturbation of cell function in Q344ter rods. Given that normal rods exhibit a range of sensitivities and kinetic behavior, with those in poorer condition usually being slower and more sensitive, the Q344ter rods may simply have been less healthy on average than the control rods. A second possibility is that the Q344ter rhodopsin's catalytic activity is quenched more slowly than that of wild-type rhodopsin, causing a slower response of larger amplitude. In principle, these two possibilities might be distinguished by observing a Q344ter rod's responses to single photons. A global perturbation should simply skew the distributions of response amplitude and duration, while a specific alteration of function in Q344ter rhodopsin might produce bimodal distributions reflecting the different activities or lifetimes of photoactivated mutant and normal rhodopsins.

In humans, a diagnosis of RP is often based upon the finding of abnormalities in the dark-adapted electroretinogram (ERG), which measures the rod-mediated flash response summed over the entire retina (Heckenlively, 1988). In many RP patients, a characteristic delay in the time interval between the light stimulus and the peak of the b-wave (the "implicit time") is observed early in the course of the disease. Over time, the amplitude of the ERG response shows a decline that parallels the degeneration of the retina. In three subjects with the Q344ter mutation the average rod-mediated ERG implicit times were 86, 87, and 94 $\mathrm{msec}$, compared to a normal value of $76 \pm 5 \mathrm{msec}$ (Jacobson et al., 1991). The slowing of transduction in single rods from Q344ter mice may represent the single-cell correlate of the lengthened ERG implicit time in RP patients. It remains to be determined whether the slowing plays a direct role in the pathogenesis of RP or represcnts a sccondary consequence of another process. The reduced flash sensitivity of RP patients has no obvious correlate in the single cell behavior that we have observed, and therefore probably results from loss of rods.

\section{Q344ter is defective in outer segment localization}

The immunolocalization experiments reported here show that in the transgenic retina Q344ter is found at high concentration both in the plasma membrane of the photoreceptor cell body and in the outer segment, while in the same retina the endogenous wild-type rhodopsin is found at appreciable concentrations only in the outer segment. This differential pattern of 
immunolocalization was observed in each of the three Q344ter transgenic lines. These results, obtained both by direct immunofluorescent double staining of single sections and by quantitative direct immunofluorescent staining of adjacent sections, imply that Q344ter is defective either in transportation to the outer segment or in retention within the outer segment. Given that the defect is restricted to the mutant protein, it seems likely that the Q344ter mutant is impaired in binding one or more components that act either to transport rhodopsin to the outer segment or to retain it within the outer segment. It is tempting to speculate that the other carboxy-terminal rhodopsin mutants are similarly impaired and that this defect may play a role in the pathogenesis of RP.

It is noteworthy that the Q344ter protein is not confined to the plasma membrane of the cell body, but is also present within the outer segment. We can clarify the possible significance of this distribution by referring to two hypothetical mechanisms for selective outer segment localization of rhodopsin. If outer segment localization of rhodopsin requires selective recognition and transportation from the cell body to the outer segment, then the Q344ter protein would appear to be partially defective in this process. If, at the other extreme, outer segment localization of rhodopsin involves passive lateral diffusion in the plasma membrane followed by selective recognition and retention in the outer segment, then the Q344ter protein could be completely defective in the latter process, since it is distributed throughout the plasma membrane in both the inner and outer segments. Alternatively, the Q344ter protein could be partially retained in the cell body because the mutation has generated a binding site for one or more cellular components. The fact that Q344ter is a truncation mutant makes this latter scenario unlikely.

For a number of receptors subcellular targeting is mediated by sequences contained within a cytosolic carboxy-terminal tail. Examples include endocytosis of the LDL receptor (Davis et al., 1987), internalization and lysosomal trafficking of the mannose6-phosphate receptor (Lobel et al., 1989), and basolateral sorting of the polymeric IgA receptor (Casanova et al., 1991). The present instance is the first example that involves targeting to a cilium-derived structure. Presumably, similar targeting systems operate in other ciliated cells, including primary olfactory and auditory neurons.

\section{Implications for the pathogenesis of $R P$}

One goal of this study was to investigate the pathophysiology of RP by constructing an animal model based upon a naturally occurring human rhodopsin mutation. While all of the Q344ter lines were found to suffer a progressive loss of photoreceptors closely resembling that found in human RP (Heckenlively, 1988), this phenotype was also observed with lines harboring wild-type rhodopsin transgenes. Among the three Q344ter transgenic lines and three of the four wild-type rhodopsin transgenic lines, the rapidity of photoreceptor degeneration roughly correlated with the level of transgene expression, ranging from less than 1 month to several months for significant photoreceptor loss. These results resemble those reported by Olsson et al. (1992) using either P23H - a class II rhodopsin mutant that is grossly defective in folding and/or stability (Sung et al., 1991b)-or wild-type human rhodopsin transgenes. Interestingly, Olsson et al. reported that degenerative changes were absent from one line that expressed transcripts from the human rhodopsin transgene at approximately the same level as the endogenous mouse rhodopsin gene. Given the rapid time course of retinal degeneration in those lines that express wild-type murine or human rhodopsin transgenes at higher levels, it will be of interest to examine this line for degenerative changes on a time scale of 1 or more years.

With respect to the pathophysiology of $R P$, the following conclusions can be drawn from the transgenic experiments reported to date. First, in the transgenic mouse models the retinal degeneration occurs far more rapidly than the 2-5 decade time course in humans, a characteristic that will be of practical utility in assaying various therapies that may slow the course of the disease. Second, rod viability is compromised by increases in rhodopsin expression, whether mutant or wild type, which suggests that gene transplacement approaches will be required to create animal models that more closely approximate the human disease. Third, in several mouse models of RP, including the Q344ter rhodopsin transgenic mice reported here, photoreceptor cell death has been shown to occur by an apoptotic mechanism as measured by internucleosomal DNA fragmentation (Chang et al., 1993; Portera-Cailliau et al., 1994). Although the mechanisms involved in triggering apoptosis remain to be elucidated, these observations suggest that a variety of primary genetic defects can lead to cell death by a final common pathway.

How might overproduction or misrouting of rhodopsin compromise cell viability? In vertebrate photoreceptors, outer segments are renewed throughout life. While the photoreceptor bears the metabolic cost of outer segment biosynthesis, the adjacent retinal pigment epithelium bears the metabolic cost of outer segment destruction. For mammalian rods the entire outer segment is turned over once every $10 \mathrm{~d}$. Rhodopsin, the most abundant protein in the outer segment, is synthesized (and destroyed) at a rate of $5 \times 10^{6}$ molecules per cell per day. In both Q344ter and wild-type transgenic mice, the source of photoreceptor damage could be related to the buildup of protein in the cell body, perhaps by producing an excessive metabolic burden associated with its destruction. This model predicts that any rhodopsin mutant that accumulates in the cell body would impair cell viability.

\section{References}

Adamus G, Arendt A, Zam ZS, McDowell JH, Hargrave PA (1988) Use of peptides to select for anti-rhodopsin antibodies with desired amino acid sequence specificities. Peptide Res 1:42-47.

Apfelstedt-Sylla E, Kunisch M, Horn M, Ruther K, Gerding H, Gal A, Zrenner $E$ (1993) Ocular findings in a family with autosomal dominant retinitis pigmentosa and a frameshift mutation altering the carboxyl terminal sequence of rhodopsin. Br J Ophthalmol 77:495-501.

Baehr W, Falk JD, Bugra K, Triantafyllos JT, McGinnis JF (1988) Isolation and analysis of the mouse opsin gene. FEBS Lett 238:253256.

Casanova JE, Apodaca G, Mostov KE (1991) An autonomous signal for basolateral sorting in the cytoplasmic domain of the polymeric immunoglobulin receptor. Cell 66:65-75.

Chang G-Q, Hao Y, Wong F (1993) Apoptosis: final common pathway of photoreceptor death in rd, rds, and rhodopsin mutant mice. Neuron 11:595-605.

Chomczinski P, Sacchi N (1987) Single step method of RNA isolation by acid guanidinium thiocyanate-phenol-chloroform extraction. Anal Biochem 162:156-159.

Davis CG, van Driel IR, Russell DW, Brown MS, Goldstein JL (1987) The low density lipoprotein receptor: identification of amino acids in the cytoplasmic domain required for rapid endocytosis. J Biol Chem 262:4075-4082.

Dryja TP, McGee TL, Hahn LB, Cowley GS, Olsson JE, Reichel E, Sandberg MA, Berson EL (1990) Mutations within the rhodopsin gene in patients with autosomal dominant retinitis pigmentosa. $\mathrm{N}$ Engl J Med 323:1302-1307.

Dryja TP, Hahn IB, Cowley GS, McGee TL, Berson EL (1991) Mutation spectrum of the rhodopsin gene among patients with autosomal dominant retinitis pigmentosa. Proc Natl Acad Sci USA 88:9370 9374. 
Farrar GJ, Kenna P, Jordan SA, Kumar-Singh R, Humphries MM, Sharp EM, Sheils DM, Humphries P (1991) A three base-pair deletion in the peripherin-RDS gene in one form of retinitis pigmentosa. Nature 354:478-480.

Fung BK-K, Stryer L (1980) Photolyzed rhodopsin catalyzes the exchange of GTP for bound GDP in retinal rod outer segments. Proc Natl Acad Sci USA 77:2500-2504.

Gal A, Artlich A, Ludwig M, Niemeyer G, Olek K, Schwinger E, Schinzel A (1991) Pro-347-Arg mutation of the rhodopsin gene in autosomal dominant retinitis pigmentosa. Genomics 11:468-470.

Gorman CM, Gies DR, McCray G (1990) Transient production of proteins using an adenovirus transformed cell line. DNA Protein Eng Tech 2:3-10.

Harlow E, Lane D (1988) Antibodies: a laboratory manual. Cold Spring Harbor, NY: Cold Spring Harbor Laboratory.

Heckenlively JR (1988) Retinitis pigmentosa Philadelphia: Lippincott.

Hicks D, Barnstable CJ (1987) Different rhodopsin monoclonal antibodies reveal different binding patterns on developing and adult rat retina. I Histochem Cytochem 35:1317-1328.

Hodges RS, Heaton RJ, Parker JM, Molday L, Molday R (1988) Antigen-antibody interaction: synthetic peptides define linear antigenic determinants recognized by monoclonal antibodies directed to the cytoplasmic carboxyl terminus of rhodopsin. J Biol Chem 263:1 176811775.

Hogan B, Constantini F, Lacy E (1986) Manipulating the mouse genome: a laboratory manual. Cold Spring Harbor, NY: Cold Spring Harbor Laboratory.

Inglehearn CF, Keen TJ, Bashir R, Jay M, Fitzke F, Bird AC, Crombie A, Bhattacharya SS (1992) A completed screen for mutations of the rhodopsin gene in a panel of patients with autosomal dominant retinitis pigmentosa. Hum Mol Genet 1:41-45.

Jacobson SG, Kemp CM, Sung C-H, Nathans J (1991) Retinal function and rhodopsin levels in autosomal dominant retinitis pigmentosa with rhodopsin mutations. Am J Ophthalmol 112:256-271.

Kajiwara K, Hahn LB, Mukai S, Travis G, Berson EL, Dryja TP (1991) Mutations in the human retinal degeneration slow gene in autosomal dominant retinitis pigmentosa. Nature 354:480-483.

Kelleher DJ, Johnson GL (1990) Characterization of rhodopsin kinase purificd from bovine rod outer segments. J Biol Chem 265:26322639.

Kemp CM, Jacobson SG, Roman AJ, Sung C-H, Nathans J (1992) Abnormal rod dark adaptation in autosomal dominant retinitis pigmentosa with proline-23-histidine rhodopsin mutation. Am J Ophthalmol 113:165-174.

Knowles A, Dartnall HJA (1977) The photobiology of vision. New York: Academic.

Konig B, Arendt A, McDowell JH, Kahlert M, Hargrave PA, Hofmann KP (1989) Three cytoplasmic loops of rhodopsin interact with transducin. Proc Natl Acad Sci USA 86:6878-6882.

Kuhn H (1982) Light regulated binding of protcins to photorcceptor membranes and its use for the purification of several rod cell proteins. Methods Enzymol 81:556-564.

Kuhn H (1984) Interactions between photoexcited rhodopsin and lightactivated enzymes in rods. Prog Retinal Res 3:123-156.

Lamb T, McNaughton PA, Yau K-W (1981) Spatial spread of activation and background desensitization in toad rod outer segments. $J$ Physiol (Lond) 319:463-496.

LaVail MM (1981) Analysis of neurological mutants with inherited retinal degeneration. Invest Ophthalmol Visual Sci 21:638-657.

Lem J, Applebury ML, Falk JD, Flannery JG, Simon MI (1991) Tissue-specific and developmental regulation of rod opsin chimeric genes in transgenic mice. Neuron 6:201-210.

Lerner RA, Green N, Alexander H, Liu F-T, Sutcliffe JG, Shinnick TM (1981) Chemically synthesized peptides predicted from the nucleotide sequence of the hepatitis $B$ virus genome elicit antibodies reactive with the native envelope protein of Dane particles. Proc Natl Acad Sci USA 78:3403-3407.

Lobel P, Fujimoto K, Ye RD, Griffiths G, Kornfeld S (1989) Mutations in the cytoplasmic domain of the 275-kD mannose 6-phosphate receptor differentially alter lysosomal enzyme sorting and endocytosis. Cell 57:787-796.

McLaughlin ME, Sandberg MA, Berson EL, Dryja T (1993) Recessive mutations in the gene encoding the beta-subunit of rod phosphodiesterase in patients with retinitis pigmentosa. Nature Genet 4:130134.
Nathans J, Hogness DS (1984) Isolation and nucleotide sequence of the gene encoding human rhodopsin. Proc Natl Acad Sci USA 81: $4851-4855$.

Nathans J, Merbs SL, Sung C-H, Weitz CJ, Wang Y (1992) Molecular genetics of human visual pigments. Annu Rev Genetics 26:401-422.

Nir I, Papermaster DS (1983) Differential distribution of opsin in the plasma membrane of frog photoreceptors: an immunocytochemical study. Invest Ophthalmol Vis Sci 24:868-878.

Nir I, Cohen D, Papermaster DS (1984) Immunocytochemical localization of opsin in the cell membrane of developing rat retinal photoreceptors. J Cell Biol 98:1788-1795.

Olsson JE, Gordon JW, Pawlyk BS, Roof D, Hayes A, Molday R, Mukai S, Cowley GS, Berson EL, Dryja TP (1992) Transgenic mice with a rhodopsin mutation (pro23his): a mouse model of autosomal dominant retinitis pigmentosa. Neuron 9:815-830.

Palczewski K, Buczylko J, Kaplan MW, Polans AS, Crabb JW (1991) Mechanism of rhodopsin kinase activation. J Biol Chem 266:1294912955.

Portera-Cailliau C, Sung C-H, Nathans J, Adler R (1994) Apoptotic photorcceptor cell death in mousc models of retinitis pigmentosa. Proc Natl Acad Sci USA 91:974-978.

Raport CJ, Lem J, Makino C, Chen C-K, Hobson A, Baylor D, Simon MI, Hurley JB (1994) Down-regulation of cGMP phosphodiesterase induced by overexpression of GTPase-deficient cone transducin in mouse rod photoreceptors. Invest Ophthalmol Vis Sci, in press.

Restagno G, Maghtheth M, Bhattacharya S, Ferrone M, Garnerone S, Samuelly R, Carbonara A (1993) A large deletion at the 3' end of the rhodopsin gene in an Italian family with a diffuse form of autosomal dominant retinitis pigmentosa. Hum Mol Genet 2:207-208.

Rohlich P, Adamus G, McDowell JH, Hargrave PA (1989) Binding pattern of anti-rhodopsin monoclonal antibodies to photoreceptor cells: an immunocytochemical study. Exp Eye Res 49:999-1013.

Rosas DJ, Roma AJ, Weissbrod P, Macke JP, Nathans J (1994) A large family with autosomal dominant retinitis pigmentosa resulting from an unusually conservative amino acid substitution, valine $345-$ to-leucine, near rhodopsin's carboxy-terminus: a clinical and molecular genetic study. Inv Ophthalmol Vis Sci, in press.

Rosenfeld PR, Cowley GS, McGee TL, Sandberg MA, Berson EL, Dryja TP (1992) A null mutation in the rhodopsin gene causes rod photoreceptor dysfunction and autosomal recessive retinitis pigmentosa. Nature Genet 1:209-213.

Sanyal S, DeRuiler A, Hawkins RK (1980) Development and degeneration of the retina in rds mutant mice: light microscopy. J Comp Neurol 194:193-207.

Shichi H, Somers RL (1978) Light dependent phosphorylation of rhodopsin: purification and properties of rhodopsin kinase. J Biol Chem 253:7040-7046.

Sitaramayya A (1986) Rhodopsin kinase prepared from bovine rod disc membranes quenches light activation of cGMP phosphodiesterase in a reconstituted system. Biochemistry 25:5460-5468.

Sung C-H, Davenport CM, Hennessey JC, Maumenee IH, Jacobson SG, Heckenlively JR, Nowakowski R, Fishman G, Gouras P, Nathans $\mathrm{J}$ (1991a) Rhodopsin mutations in autosomal dominant retinitis pigmentosa. Proc Natl Acad Sci USA 88:6481-6485.

Sung C-H, Schneider BG, Agarwal N, Papermaster DS, Nathans J (1991b) Functional heterogeneity of mutant rhodopsins responsible for autosomal dominant retinitis pigmentosa. Proc Natl Acad Sci USA 88:8840-8844.

Sung C-H, Davenport CM, Nathans J (1993) Rhodopsin mutations responsible for autosomal dominant retinitis pigmentosa: clustering of functional classes along the polypeptide chain. J Biol Chem 268: 26645-26649.

Tamura T, Nakatani K, Yau K-W (1989) Light adaptation in cat retinal rods. Science 245:755-758.

Wang Y, Macke JP, Merbs SL, Klaunberg B, Bennett J, Zack D, Gearhart J, Nathans J (1992) A locus control region adjacent to the human red and green pigment genes. Neuron 9:429-440.

Wilden U, Hall SW, Kuhn H (1986) Phosphodiesterase activation by photoexcited rhodopsin is quenched when rhodopsin is phosphorylated and binds the intrinsic $48-\mathrm{kDa}$ protein of rod outer segments. Proc Natl Acad Sci USA 83:1174-1178.

Zack DJ, Bennett J, Wang Y, Davenport C, Klaunberg B, Gearhart J, Nathans J (1991) Unusual topography of bovine rhodopsin promoter-lacZ fusion gene expression in transgenic mouse retinas. Neuron 6:187-199. 